\title{
Breast milk immune complexes are potent inducers of oral tolerance in neonates and prevent asthma development
}

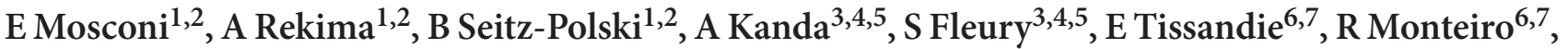 \\ DD Dombrowicz $^{3,4,5}$, V Julia $^{1,2}, N_{\text {Glaichenhaus }}^{1,2}$ and V Verhasselt ${ }^{1,2}$
}

\begin{abstract}
Allergic asthma is a chronic lung disease resulting from an inappropriate Thelper (Th)-2 response to environmental antigens. Early tolerance induction is an attractive approach for primary prevention of asthma. Here, we found that breastfeeding by antigen-sensitized mothers exposed to antigen aerosols during lactation induced a robust and long-lasting antigen-specific protection from asthma. Protection was more profound and persistent than the one induced by antigen-exposed non-sensitized mothers. Milk from antigen-exposed sensitized mothers contained antigen-immunoglobulin (lg) $\mathrm{G}$ immune complexes that were transferred to the newborn through the neonatal Fc receptor resulting in the induction of antigen-specific FoxP3 ${ }^{+} \mathrm{CD}_{2} 5^{+}$regulatory $\mathrm{T}$ cells. The induction of oral tolerance by milk immune complexes did not require the presence of transforming growth factor- $\beta$ in milk in contrast to tolerance induced by milk-borne free antigen. Furthermore, neither the presence of IgA in milk nor the expression of the inhibitory Fc $\gamma$ RIllb in the newborn was required for tolerance induction. This study provides new insights on the mechanisms of tolerance induction in neonates and highlights that IgG immune complexes found in breast milk are potent inducers of oral tolerance. These observations may pave the way for the identification of key factors for primary prevention of immune-mediated diseases such as asthma.
\end{abstract}

\section{INTRODUCTION}

Early life is a challenging period for the immune system: it faces massive antigenic challenge due to microbial colonization and exposure to environmental antigens and at the same time has to maintain low levels of inflammation to allow harmonious organ development. Pioneer studies by Medawar have suggested that neonates are immunologically immature and prone to tolerance induction. Later works showed that neonates are biased for Thelper (Th)-2 responses as compared to adults but also that any kind of immune response could be induced in neonates under appropriate condition. ${ }^{1}$ How the immune system responds to antigenic challenge in early life probably influences susceptibility to immune-mediated disorders and in particular to those that develop in childhood such as autoimmune diabetes and allergic diseases. ${ }^{2}$

Among allergic diseases, allergic asthma is a major public health concern affecting 300 million people and belonging to the leading causes of morbidity in children. ${ }^{3}$ The pathogenesis of this chronic lung inflammatory disease involves a sensitization step where $\mathrm{CD} 4{ }^{+} \mathrm{T}$ cells are primed in response to normally innocuous inhaled allergens and differentiate toward a Th2 phenotype. Some of these sensitized patients will develop asthma, a disease that is characterized by acute respiratory difficulties after allergen inhalation due to mucus accumulation and airway inflammation and more chronic symptoms due to lung remodeling. ${ }^{4,5}$ Early immune modulation aimed at impeding allergen sensitization is an attractive approach for primary prevention of asthma.

For years, breast milk was considered mainly as a source of nutrients for the developing child. The extensive observations that breastfeeding affords protection toward infectious diseases and reduces mortality due to common infections by more than half have added another key role to breastfeeding. ${ }^{6}$ Protection mainly relies on passive immunity due to the transfer of high

\footnotetext{
${ }^{1}$ INSERM, U924, Valbonne, France. ${ }^{2}$ Université de Nice-Sophia-Antipolis, Valbonne, France. ${ }^{3}$ INSERM, U547, Lille, France. ${ }^{4}$ Université Lille Nord de France, Lille, France. ${ }^{5}$ Institut Pasteur, Lille, France. ${ }^{6}$ Inserm U699, Paris, France. ${ }^{7}$ Université Paris 7-Denis Diderot, Paris, France. Correspondence: V Verhasselt (verhasselt@ipmc.cnrs.fr) 
amounts of microbe-specific immunoglobulin (Ig) that compensate for the deficiency of Ig synthesis during the first year of life. ${ }^{7}$ In addition, recent studies have shown that breastfeeding actively shapes progeny's immune response both through its effect on gut flora and through the transfer of various immune mediators. ${ }^{6}$ Epidemiological studies on the protection from allergic diseases upon breastfeeding have yielded conflicting results, whether or not the allergic status of the mothers was taken into account. ${ }^{8-11}$ In a meta-analysis of prospective studies ${ }^{10}$ and in a multidisciplinary review ${ }^{8}$ of studies performed between 1966 and 2000, the authors concluded that breastfeeding protection was higher in the subgroup of children with a positive family history of asthma or atopy. Two more recent prospective studies on a birth cohort of 4,089 (ref. 12) and 3,115 children, ${ }^{13}$ respectively, did not show increased protection in the case of heredity for allergy. Finally, in a prospective study on 1,200 children, breastfeeding did not protect children against atopy or asthma and could even increase the risk of asthma in children with a parental history of asthma. ${ }^{14}$ Of note, allergen exposure of the mothers was not recorded in these studies. We have recently formulated the hypothesis that protection from asthma through breastfeeding relies on immune tolerance induction and requires antigen transfer to the child through breast milk. ${ }^{15}$ In a mouse model, we have shown that protection against asthma through breastfeeding required the exposition of the mothers to the allergen during lactation. The presence of the allergen together with transforming growth factor- $\beta$ (TGF- $\beta$ ) in breast milk was necessary to induce the development of regulatory $\mathrm{T}\left(\mathrm{T}_{\text {reg }}\right)$ cells in the progeny and their partial protection from asthma development. In that study, mothers were not sensitized to the inhaled antigen. Here, we have investigated whether breastfeeding by allergic mothers would affect asthma development in the progeny.

\section{RESULTS}

\section{Breastfeeding by antigen-exposed sensitized mothers induces a profound and long-lasting antigen-specific protection from allergic airway inflammation}

The development of the newborn immune system is influenced by maternal factors that are transferred from the mother to the progeny in utero and through breastfeeding. To assess whether allergic mothers can induce protection from allergic airway inflammation through breast milk, we fostered pups born from naive mothers by non-sensitized or ovalbumin (OVA)-sensitized mothers that were exposed or not to OVA aerosols during lactation. These mothers will be referred as "OVA-exposed" or "unexposed", "sensitized" or "non-sensitized" thereafter (Figure 1a). When 6-8 weeks old, fostered mice were sensitized, challenged with OVA aerosols, and analyzed for features of allergic airway disease (Figure 1a). As we previously published, mice breastfed by OVA-exposed nonsensitized mothers were partially protected from asthma ${ }^{15}$ (Figure 1b-f). Although mice breastfed by unexposed sensitized mothers were not protected, exposition of sensitized mothers to OVA aerosols during lactation resulted in a profound and reproducible inhibition of allergic airway disease in the breastfed pups. Airway hyperreactivity was dramatically reduced even in response to high doses of methacholine (Figure 1b); total cell and eosinophil numbers in bronchoalveolar lavage (BAL) fluids were similar to those found in naive mice (Figure 1c); secretion of interleukin (IL)-4, IL-5, IL-10, and IL-13 by lung cells was greatly inhibited (Figure 1d); serum OVA-specific IgE, IgG1, and IgG2a were close to the lower limit of detection (Figure 1e); and lung inflammation was extremely scarce (Figure 1f). TGF- $\beta$ and interferon- $\gamma$ levels were similar in all groups (data not shown). Strikingly, all parameters of allergic airway disease were more profoundly inhibited in mice breastfed by OVA-exposed sensitized mothers as compared to those breastfed by OVA-exposed non-sensitized mothers: 62 vs. $42 \%$ of inhibition for resistance at the highest methacholine concentration; 96 vs. $76 \%$ for eosinophilic airway inflammation; 94 vs. $67 \%$ for OVA-specific IgE levels; 80 vs. $70 \%$ for lung IL-4 levels, 66 vs. $44 \%$ for IL-5, 72 vs. $45 \%$ for IL-10, and 88 vs. $54 \%$ for IL-13.

To assess whether protection was long lasting, we immunized mice breastfed by OVA-exposed sensitized or non-sensitized mothers 14 weeks after birth and challenged them with OVA aerosols. Representative features of allergic airway disease such as eosinophilic airway inflammation, serum levels of OVA-specific IgE, and lung IL-13 and IL-5 secretion

Figure 1 Allergic airway disease in mice breastfed by ovalbumin (OVA)-exposed sensitized mothers. (a) Schematic representation of the experimental protocol. Adult BALB/c female mice were sensitized or not with two injections of OVA in alum before mating. Pups from sensitized mothers were killed at birth and replaced by pups from non-sensitized mothers. Non-sensitized and sensitized mothers were then exposed or not exposed to OVA aerosols every other day from delivery until weaning. When 6- to 8-week-old, offspring were sensitized with two intraperitoneal injections of OVA in alum and challenged daily for 5 days with OVA aerosols. Mice were analyzed 1 day after the last aerosol. (b) Airway hyperreactivity (AHR). Dynamic lung resistance and compliance were monitored in mice breastfed by unexposed (filled circle) or OVA-exposed (empty circle) non-sensitized mothers, or unexposed (filled square) or OVA-exposed (empty square) sensitized mothers upon sensitization and challenge with OVA; $n=6-7$ mice per group in each experiment. Non-sensitized mice challenged with OVA (triangle) were used as controls; $n=3$ in each experiment. Data are expressed as mean \pm S.e.m. and are representative of one experiment out of two. ${ }^{* \star} P<0.01$. (c-e) OVA-sensitized and challenged mice breastfed by unexposed (empty bars) or OVA-exposed (light gray bars) non-sensitized mothers, or unexposed (dark gray bars) or OVA-exposed (black bars) sensitized mothers were analyzed for allergic airway inflammation. Non-sensitized mice challenged with OVA (hatched bars) were used as controls. Number and phenotype of cells in bronchoalveolar lavage (BAL) fluids (c), cytokine secretion by lung cells incubated or not with OVA (d), and serum levels of OVA-specific $\lg (\mathbf{e})$. Data are expressed as mean \pm s.e.m. of seven experiments with $n=6-8$ mice per group in each experiment. ${ }^{* \star *} P<0.0001 ;{ }^{* \star *} P<0.001 ;{ }^{* \star} P<0.01 ;{ }^{*} P<0.05$; NS, $P>0.05$. (f) Histology of lung sections. Lungs from the indicated mice were sectioned and stained with Periodic Acid of Schiff (PAS) (upper panel) or May-Grünwald Giemsa (MGG) (lower panel). Data show representative microscopic images at a 10-fold magnification. 
a

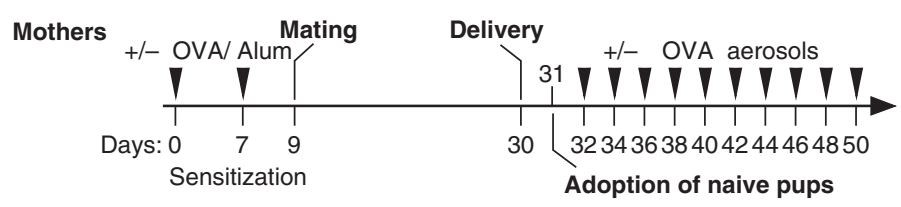

Progeny (6-8 weeks old)

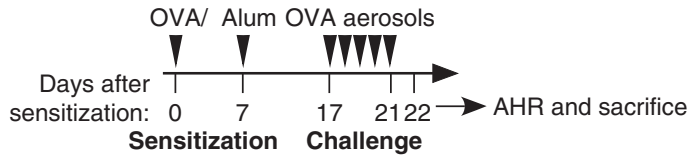

C

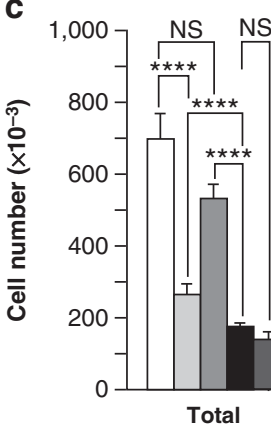

Challenge

osinophils Neutrophils Lymphocytes Macrophages

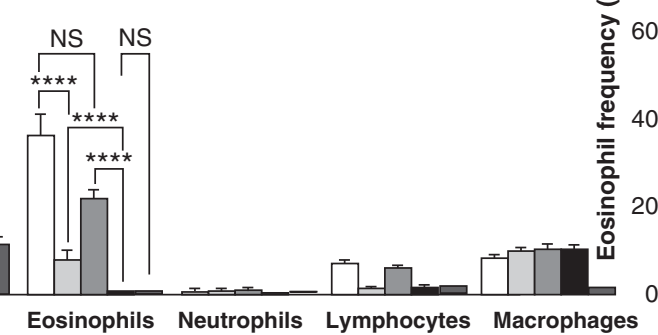

d
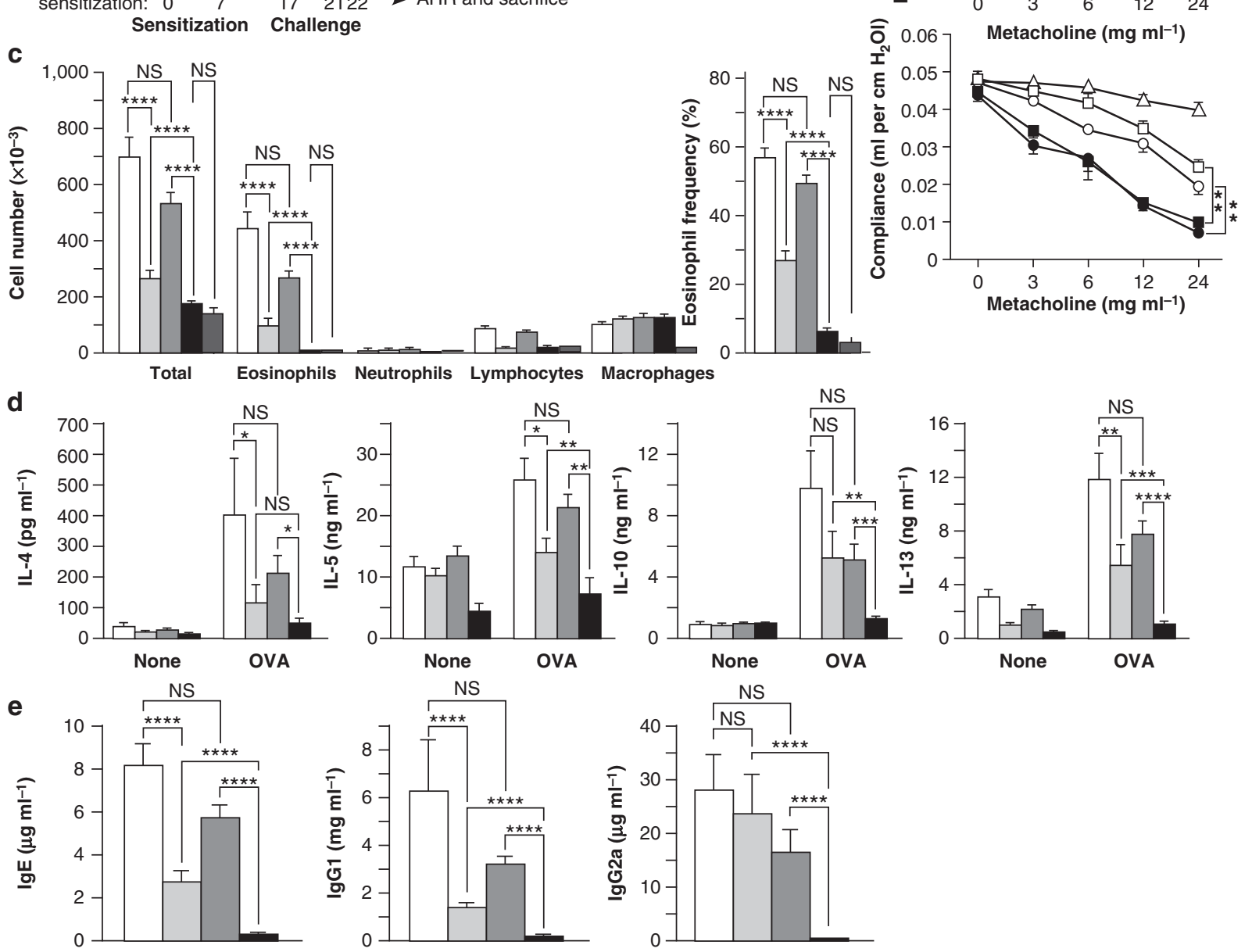

f

Pups breastfed by

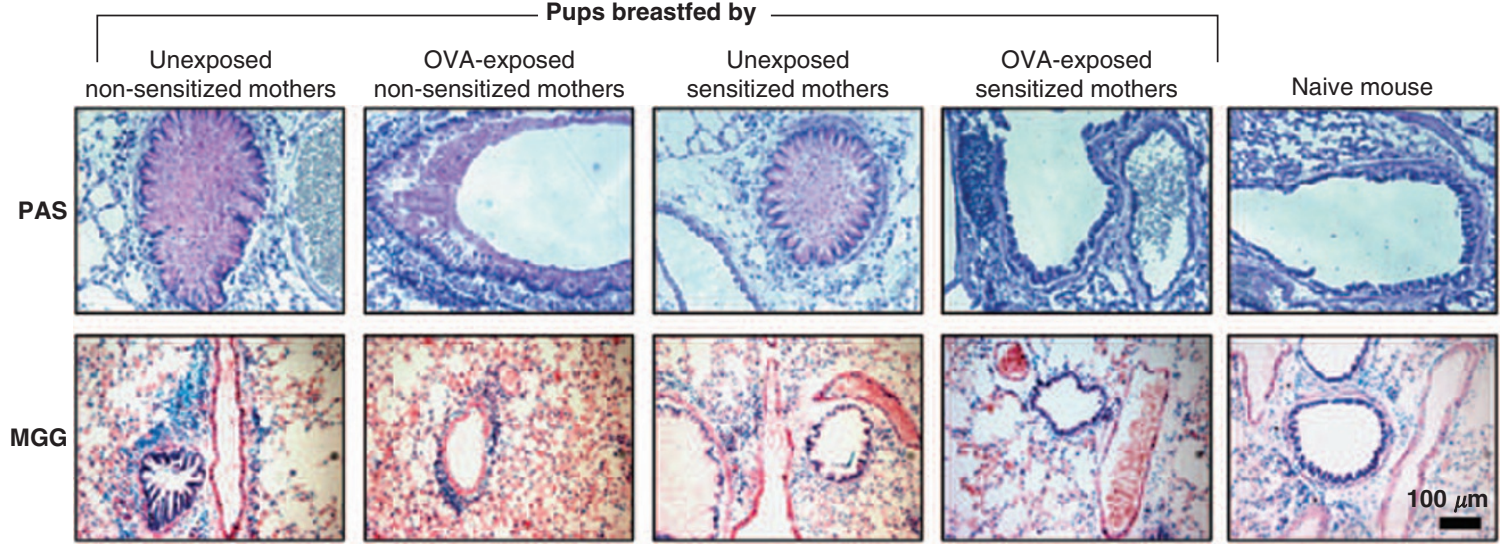



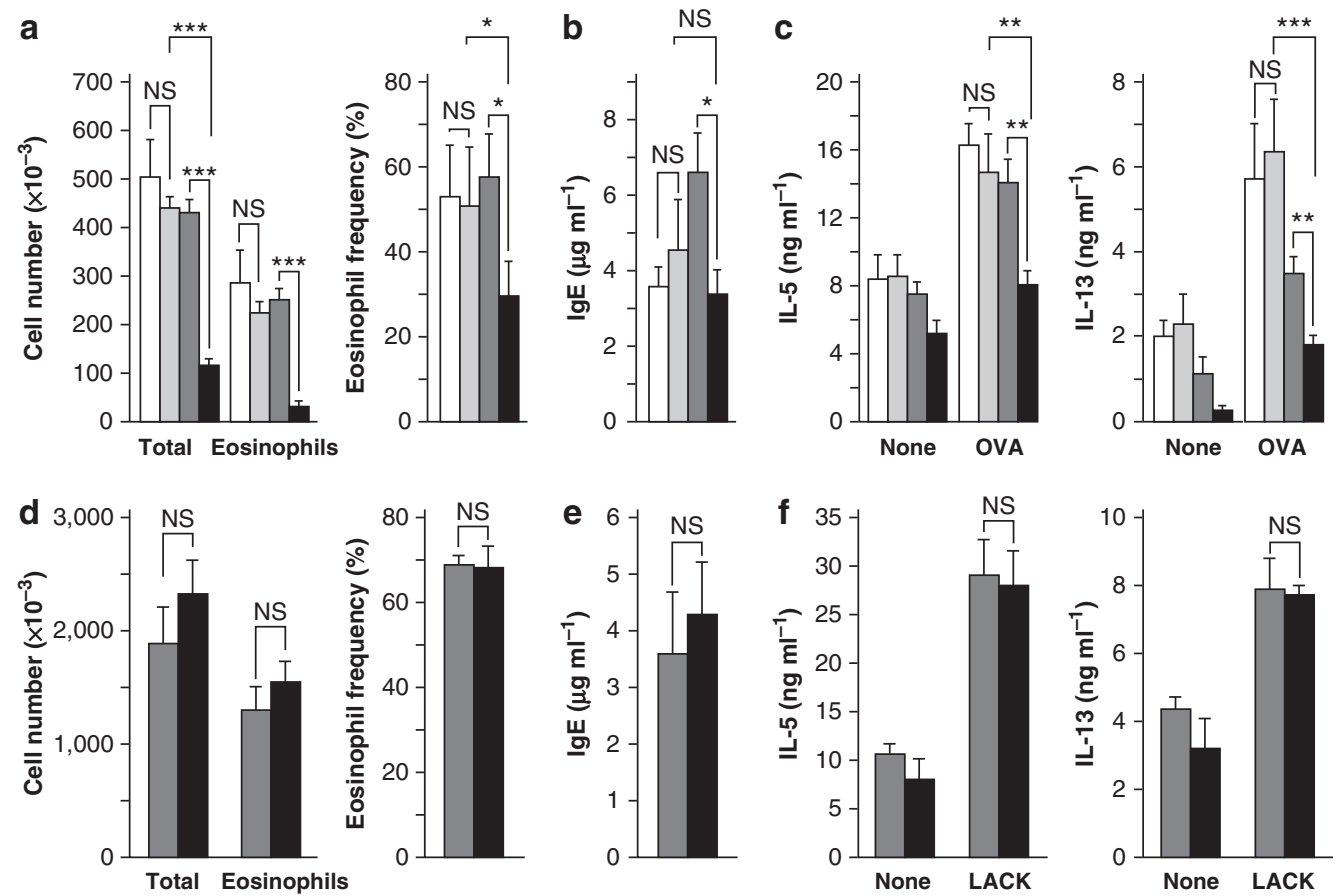

Figure 2 Breastfeeding-induced protection by ovalbumin (OVA)-exposed sensitized mothers is long lasting and antigen specific. (a-c) Long-term protection. Mice were breastfed by unexposed (empty bars) or OVA-exposed (light gray bars) non-sensitized mothers, or unexposed (dark gray bars) or OVA-exposed (black bars) sensitized mothers. Mice were sensitized and challenged with OVA 14 weeks after birth. Data show cell number and eosinophils frequency in bronchoalveolar lavage (BAL) fluids (a), serum levels of OVA-specific IgE (b), and levels of interleukin (IL)-5 and IL-13 secreted by lung cells when incubated or not with OVA (c). Data are expressed as mean \pm s.e.m. in one representative experiment with $n=9$.

(d-f) Antigen specificity. Mice were breastfed by unexposed (dark gray bars) or OVA-exposed (black bars) sensitized mothers, sensitized with LACK when they were 6-8 weeks old, and then challenged with LACK aerosols. Data show cell number and frequency of eosinophils in BAL fluid (e), serum levels of LACK-specific IgE content (f), and levels of IL-5 and IL-13 secreted by lung cells when incubated or not with LACK (g). Data are expressed as mean \pm s.e.m. in one representative experiment with $n=8$. ${ }^{\star \star \star} P<0.001 ;{ }^{* \star} P<0.01 ;{ }^{\star} P<0.05 ; \mathrm{NS}, P>0.05$.

Table 1 Levels of OVA-specific Ig in milk

\begin{tabular}{lcccc}
\hline & & \multicolumn{2}{c}{ OVA-specific Ig Concentration in milk $\left(\mu \mathrm{m} \mathrm{ml}^{-1}\right)$} \\
\cline { 2 - 5 } & $\begin{array}{c}\text { Unexposed non- } \\
\text { sensitized mothers }\end{array}$ & $\begin{array}{c}\text { OVA-exposed non- } \\
\text { sensitized mothers }\end{array}$ & $\begin{array}{c}\text { Unexposed } \\
\text { sensitized mothers }\end{array}$ & $\begin{array}{c}\text { OVA-exposed } \\
\text { sensitized mothers }\end{array}$ \\
\hline IgA & $<0.5$ & $<0.5$ & $<0.5$ & $23 \pm 3$ \\
IgG2a & $<0.5$ & $<0.5$ & $<0.5$ & $5.2 \pm 2$ \\
IgG1 & $<0.5$ & $1.0 \pm 0.3$ & $6.7 \pm 1.8$ & $118 \pm 23$ \\
\hline
\end{tabular}

Abbreviations: Ig, immunoglobulin; OVA, ovalbumin.

Breast milk from unexposed or OVA-exposed non-sensitized or sensitized mothers was collected, pooled, and analyzed for the presence of OVA-specific IgA, IgG2a, and IgG1 by ELISA. Data show the mean \pm s.e.m. of six experiments.

remained profoundly decreased in mice breastfed by OVAexposed sensitized mothers but not in those breastfed by OVA-exposed non-sensitized mothers (Figure 2a-c). Further experiments showed that mice breastfed by OVA-exposed sensitized mothers were protected from allergic airway disease induced by OVA, but not by the unrelated Leishmania LACK antigen ${ }^{16}$ (Figure 2d-f). Therefore, breastfeedinginduced protection conferred by OVA-exposed sensitized mothers was antigen specific. Altogether, our data show that breastfeeding by antigen-sensitized mothers induces a profound, reproducible, and long-lasting antigen-specific protection as far as the mothers are exposed to the antigen during lactation.
Breastfeeding-induced protection by OVA-exposed sensitized mothers does not require maternal IgA or TGF- $\beta$ in milk

IgA exert an immunoregulatory role in mice and are associated with immune tolerance in humans. ${ }^{17-20}$ OVA-specific IgA were found in the milk of OVA-exposed sensitized mothers, but not in those of unexposed sensitized mothers or OVA-exposed or unexposed non-sensitized mothers (Table 1). To further assess the role of IgA in breastfeeding-induced protection, we used a neutralizing anti-CCL28 monoclonal antibody $(\mathrm{mAb})$ that blocks the accumulation of IgA-secreting cells in the mammary gland and thereby IgA secretion into milk. ${ }^{21}$ Administration of anti-CCL28 $\mathrm{mAb}$ to OVA-exposed sensitized mothers during lactation resulted in a drop of total IgA in milk from 131 to 

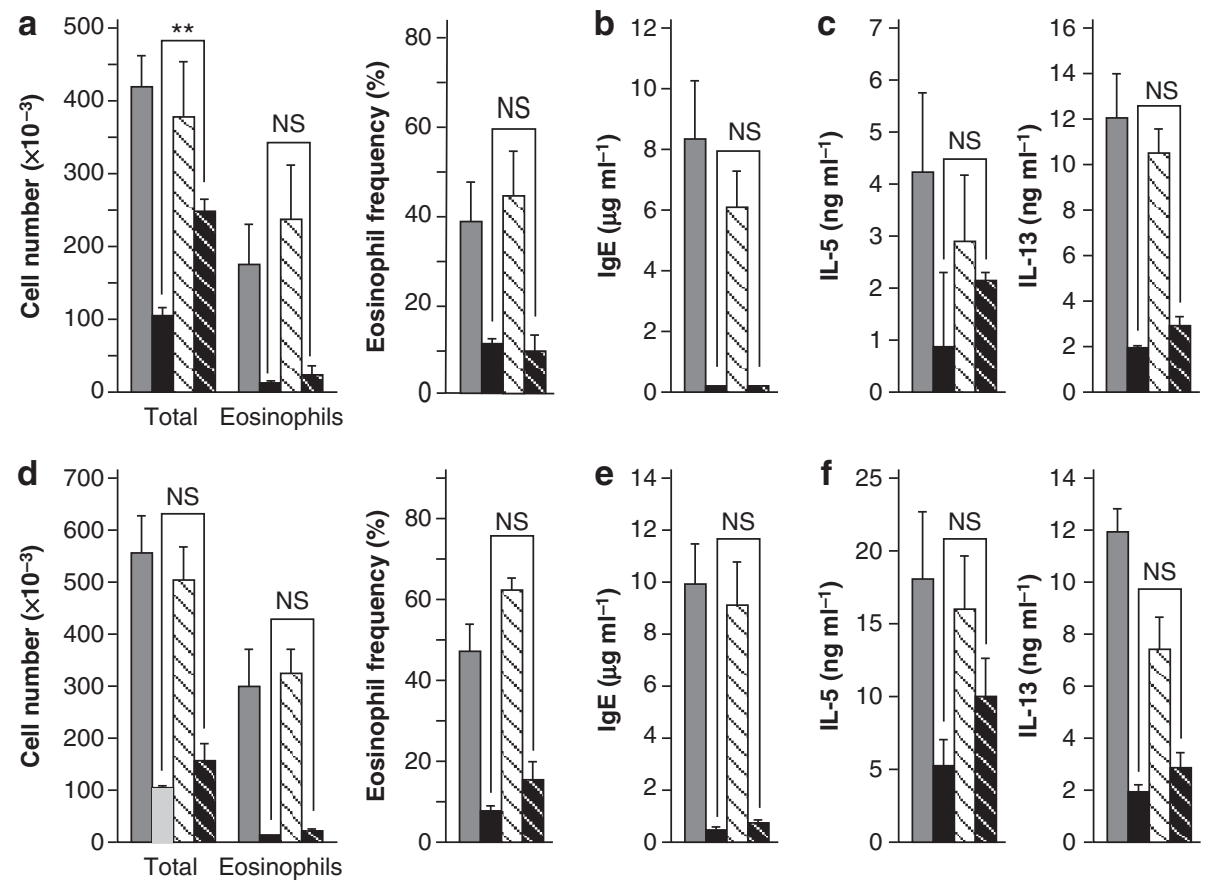

Figure 3 Breastfeeding-induced protection by ovalbumin (OVA)-exposed sensitized mothers does not require neither IgA nor transforming growth factor (TGF)- $\beta$ in milk. Allergic airway disease in mice breastfed by sensitized mothers treated with anti-CCL28 mAb (a-c) or with antiTGF- $\beta$ mAb (d-f). Pups were breastfed by unexposed (gray bars) or OVA-exposed (black bars) sensitized mothers treated with isotypic control monoclonal antibody ( $\mathrm{mAb}$ ), or unexposed (dashed white bars) or OVA-exposed (dashed black bars) sensitized mothers treated with anti-CCL28 $(\mathbf{a}-\mathbf{c})$ or anti-TGF- $\beta$ mAb (d-f). Data show cell number and eosinophils frequency in bronchoalveolar lavage (BAL) fluids (a and d), serum levels of OVA-specific IgE (b and $\mathbf{e}$ ), and levels of IL-5 and IL-13 secreted by lung cells when incubated with OVA (c and f). Data are expressed as mean \pm S.e.m. of two experiments for anti-TGF- $\beta$ experiment and one experiment for anti-CCL28 experiment with $n=7$ mice per group. ${ }^{* \star} P<0.01$; NS, $P>0.05$.

$18 \mu \mathrm{g} \mathrm{ml}^{-1}$ and in a reduction of OVA-specific IgA from 25 to $1.4 \mu \mathrm{g} \mathrm{ml}^{-1}$ (pool of three individuals). Mice breastfed by antiCCL28 mAb-treated OVA-exposed sensitized mothers remained protected as shown by measuring airway eosinophilia, serum levels of OVA-specific IgE, and IL-5 and IL-13 secretion in their lungs (Figure 3a-c).

Breast milk contains high levels of the immunosuppressive cytokine TGF- $\beta .{ }^{6}$ To investigate the role of TGF- $\beta$ in breastfeeding-induced tolerance by sensitized mothers, we treated OVA-exposed sensitized mothers with anti-TGF- $\beta$ or control isotypic $\mathrm{mAb}$ during lactation. As previously published, the intraperitoneal administration of $1 \mathrm{mg}$ of anti-TGF- $\beta \mathrm{mAb}$ to lactating mothers twice a week resulted in a nearly total neutralization of milk TGF- $\beta .{ }^{15}$ Eosinophil numbers in BAL fluids, OVA-specific IgE levels in serum, and IL-13 and IL-5 lung secretion were similarly decreased in mice breastfed by OVA-exposed sensitized mothers treated with anti-TGF- $\beta$ or control isotypic mAb (Figure 3d-f). Therefore, milk-borne TGF- $\beta$ was not necessary for breastfeeding-induced protection by OVA-exposed sensitized mothers. In addition, when OVA-exposed sensitized mothers were treated with antiTGF- $\beta$ mAb, OVA-specific IgA levels in milk were greatly reduced ( $0.6 \mathrm{vs.} 25 \mu \mathrm{g} \mathrm{ml}^{-1}$, pool of three individuals) further showing that OVA-specific IgA were not required for breastfeeding-induced protection by OVA-exposed sensitized mothers.

\section{Milk of OVA-exposed sensitized mothers contains OVA-lgG immune complexes}

Circulating maternal IgG have been proposed to inhibit Th2 responses in the offspring of antigen-sensitized rodents. ${ }^{5,22-28}$ Therefore, we measured the levels of OVA-specific IgG in the milk of OVA-exposed sensitized mothers and in the sera of their breastfed pups. Both OVA-specific IgG1 and IgG2a were present in the milk of OVA-exposed sensitized mothers (Table 1). The levels of OVA-specific IgG1 were 20-fold higher than those of IgG2a (Table 1). Moreover, OVA-specific IgG1 levels were 20-fold higher in the milk of OVA-exposed sensitized mothers than in unexposed sensitized mothers and close to or below the lower limit of detection in OVA-exposed and unexposed nonsensitized mothers (Table 1). OVA-specific IgG1 and IgG2a were also found in sera of pups breastfed by OVA-exposed sensitized mothers (Table 2a and b). OVA-specific IgG2a levels were only found in sera before weaning and at levels 50 times lower than those of IgG1 (Table 2a). Although high levels of OVA-specific IgG1 were found in the serum of 2-week-old newborns pups breastfed by OVA-exposed sensitized mothers $\left(11 \pm 1.9 \mathrm{mg} \mathrm{ml}^{-1}\right.$; mean \pm s.e.m.; $n=6$ ), this level dropped to $0.2 \mathrm{mg} \mathrm{ml}^{-1}$ at $6-8$ weeks and OVA-specific IgG1 were undetectable at 14 weeks (Table 2b). Because breastfeeding-induced protection by OVAexposed sensitized mothers was still effective in 14-week-old mice (Figure 2a), this latter result suggests that circulating OVAspecific IgG were not directly responsible for the inhibition of 
Table 2 Serum levels of OVA-specific IgG2a and IgG1 in mice breastfed by OVA-exposed sensitized mothers

\begin{tabular}{|c|c|c|c|c|}
\hline Age & $\begin{array}{l}\text { Unexposed non- } \\
\text { sensitized mothers }\end{array}$ & $\begin{array}{l}\text { OVA-exposed non- } \\
\text { sensitized mothers }\end{array}$ & $\begin{array}{c}\text { Unexposed } \\
\text { sensitized mothers }\end{array}$ & $\begin{array}{l}\text { OVA-exposed } \\
\text { sensitized mothers }\end{array}$ \\
\hline \multicolumn{5}{|c|}{ (a) OVA-specific IgG2a in serum of newborns $\left(\mu g \mathrm{ml}^{-1}\right)$} \\
\hline 7 weeks & $<0.01$ & $<0.01$ & $<0.01$ & $<0.01$ \\
\hline 14 weeks & $<0.01$ & $<0.01$ & $<0.01$ & $<0.01$ \\
\hline 7 weeks & $<0.001$ & $<0.001$ & $0.013 \pm 0.002$ & $0.235 \pm 0.039$ \\
\hline 14 weeks & $<0.001$ & $<0.001$ & $<0.001$ & $<0.001$ \\
\hline
\end{tabular}

Abbreviations: Ig, immunoglobulin; OVA, ovalbumin.

The sera of newborns breastfed by unexposed or OVA-exposed non-sensitized or sensitized mothers were harvested 2, 7 , and 14 weeks after birth and analyzed for the presence of OVA-specific IgG2a (Table 2a) and IgG1 (Table $\mathbf{2 b}$ ) by ELISA. Data are expressed as mean \pm s.e.m. with $n=9$.

Th2 responses in mice that have been breastfed by OVA-exposed sensitized mothers.

We next assessed whether OVA was present in the milk of OVA-exposed sensitized mothers. OVA was readily detected both by enzyme-linked immunosorbent assay (ELISA) and by western blot analysis (Figure 4a). As previously published, ${ }^{15}$ we also found that OVA was present in the milk of OVAexposed non-sensitized mothers. OVA levels in milk were 10 -fold lower in sensitized mothers than non-sensitized mothers ( $29 \pm 8$ vs. $342 \pm 21 \mathrm{ng} \mathrm{ml}^{-1}$; mean \pm s.e.m.; $\left.n=6\right)$. As the milk of OVA-exposed sensitized mothers contained both OVA and OVA-specific IgG, we investigated whether it also contained OVA-IgG immune complexes. OVA-IgG1 immune complexes were readily detected in the milk of OVA-exposed sensitized mothers and at much lower levels in the milk of OVA-exposed non-sensitized mothers (Figure $\mathbf{4 b}$, left panel). To determine the proportion of OVA that was engaged in immune complexes, we depleted the milk of OVA-exposed sensitized mothers of IgG with protein $\mathrm{G}$ before being analyzed by western blot using an anti-OVA mAb. Results showed that $85 \%$ of OVA was bound to IgG in the milk of OVA-exposed sensitized mothers (Figure $\mathbf{4 b}$, right panel). Molecular size of OVA-IgG immune complexes was determined after gel filtration of the milk from OVA-exposed sensitized mothers and analysis by ELISA for the presence of OVA-IgG1 immune complexes in the collected fractions (Figure 4c). OVA-IgG1 immune complexes were found in the fractions corresponding to proteins of $500-2,000 \mathrm{kDa}$ molecular weight. Further experiments showed that OVA-IgG1 immune complexes were present in the serum of 2-week-old pups breastfed by OVA-exposed sensitized mothers (Figure 5a).

\section{FcRn is necessary for breastfeeding-induced protection by OVA-exposed sensitized mothers}

The expression of the neonatal $\mathrm{Fc}$ receptor $(\mathrm{FcRn})$ on epithelial cells in the small proximal intestine allows an active and protected transport of maternally derived IgG from breast milk to the pups. ${ }^{29,30} \mathrm{FcRn}$ is expressed on intestinal epithelial cells in rodents until weaning and in humans throughout life. In adult transgenic mice expressing the human FcRn, this receptor allows the transfer of IgG immune complexes across the intestinal barrier allowing subsequent retrieval of luminal antigens. ${ }^{31}$ The presence of OVA-IgG immune complexes in the serum of 2 -week-old pups breastfed by OVA-exposed sensitized mothers shows a protected transfer of these immune complexes from mother's milk to their pup and suggests a role for the FcRn in this transport (Figure 5a). Accordingly, we observed that the levels of OVA-IgG immune complexes were profoundly decreased in the serum of FcRn-deficient mice breastfed by OVA-exposed sensitized mothers indicating a crucial role for this receptor in the transfer OVA-IgG immune complexes from mother's milk to the pup (Figure 5a). Because OVA was almost entirely found associated to immune complexes in the milk of OVA-exposed sensitized mothers, we predicted that FcRn-deficient mice would not become tolerant to OVA when breastfed by OVA-exposed sensitized mothers. To test this hypothesis, we fostered $\mathrm{FcRn}$-deficient and wild-type (wt) $\mathrm{C} 57 \mathrm{Bl} / 6$ pups by unexposed and by OVA-exposed sensitized mothers. Similar to $\mathrm{BALB} / \mathrm{c}$ mice, $\mathrm{C} 57 \mathrm{Bl} / 6$ breastfed by OVA-exposed sensitized mothers were protected from allergic airway disease development as shown by a decrease in eosinophilic airway inflammation, IL-5 and IL-13 lung secretion, and serum OVA-specific IgG1 (IgE are not detected in C57Bl/6 mice in the model we use for asthma induction) as compared to mice breastfed by unexposed sensitized mothers (Figure $\mathbf{5 b} \mathbf{b}-\mathbf{d}$ ). In contrast, protection was totally abrogated in FcRn-deficient mice breastfed by OVA-

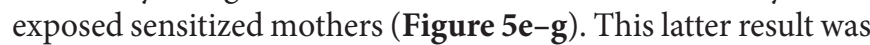
not due to an intrinsic inability of FcRn-deficient mice to mount tolerance as FcRn-deficient mice were tolerant when breastfed by OVA-exposed non-sensitized mothers (Supplementary Figure 2). These data strongly suggest that the FcRn-mediated transfer of OVA-IgG immune complexes from mother's milk to their pups is critical for tolerance induction by OVA-exposed sensitized mothers.

\section{Fc $\gamma \mathrm{R}$ Ilb is not required for breastfeeding-induced protection} by OVA-exposed sensitized mothers

Fc $\gamma$ RIIb (CD32b) belongs to the family of immune inhibitory receptors that carry an immunoreceptor tyrosine-based inhibition motif. When colligated to the B-cell receptor, 

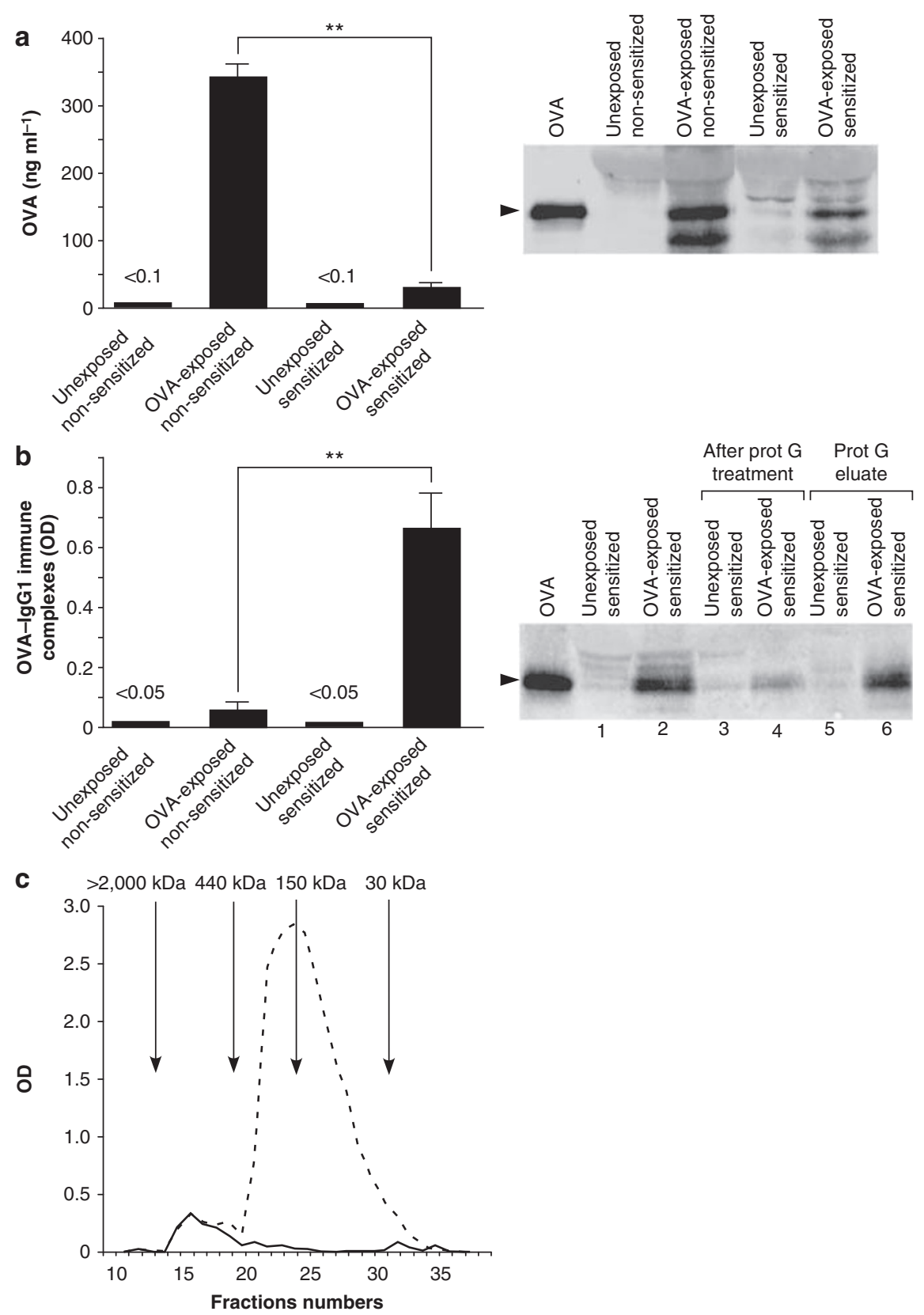

Figure 4 Ovalbumin (OVA) and OVA-IgG immune complexes in breast milk. Sensitized and non-sensitized mothers were exposed or not exposed to OVA and breast milk was collected $6 \mathrm{~h}$ later. (a) OVA levels in breast milk. The milk from the indicated mice was analyzed for OVA content by enzymelinked immunosorbent assay (ELISA) (left panel) or western blot (right panel). For ELISA, data show mean \pm s.e.m. of six independent experiments. For western blot, the result from one representative experiment of three is shown. OVA was used as a control (left lane). (b) OVA-IgG immune complexes in milk. The milk from the indicated mice was analyzed for OVA-IgG1 content by ELISA (left panel), and for OVA content by western blot directly or after removal of protein G-bound material (right panel). For ELISA, data show the mean \pm s.e.m. of values obtained in six independent experiments. For western blot, the milk from unexposed (lanes 1, 3, and 5) and from OVA-exposed (lanes 2, 4, and 6) sensitized mothers was analyzed directly (lanes 1 and 2) or after removal of protein G-bound material (lanes 3 and 4). Protein G-bound material was eluted and analyzed (lanes 5 and 6 ). OVA in phosphate-buffered saline (PBS) was used as a control (left lane). One representative experiment out of two is shown. ${ }^{\star \star} P<0.01$. (c) Levels of OVA-lgG immune complexes and OVA-specific IgG in FPLC fractionated milk. The milk from OVA-exposed sensitized mice was fractionated on FPLC and the fractions corresponding to proteins of the indicated MW were collected and analyzed by ELISA for the presence of OVA-specific IgG1 (dashed line) and OVA-IgG1 immune complexes (solid line). Data show the results of one representative experiment out of four for the milk of OVA-exposed sensitized mice. When the milk of naive mice was analyzed, none of the fractions gave a positive signal.

Fc $\gamma$ RIIb inhibits B-cell activation and proliferation, induces apoptosis, and is critical for B-cell tolerance to self-antigens as shown by the development of lupus-like disease in Fc $\gamma$ RIIb-deficient mice. Fc $\gamma$ RIIb is also involved in T-cell tolerance through its expression on dendritic cells (DCs)..$^{32-35}$ To assess whether Fc $\gamma$ RIIb is involved in tolerance induced by OVA-exposed sensitized mothers, wt $\mathrm{C} 57 \mathrm{Bl} / 6$ mice or Fc $\gamma$ RIIb-deficient pups were breastfed by OVA-exposed or 

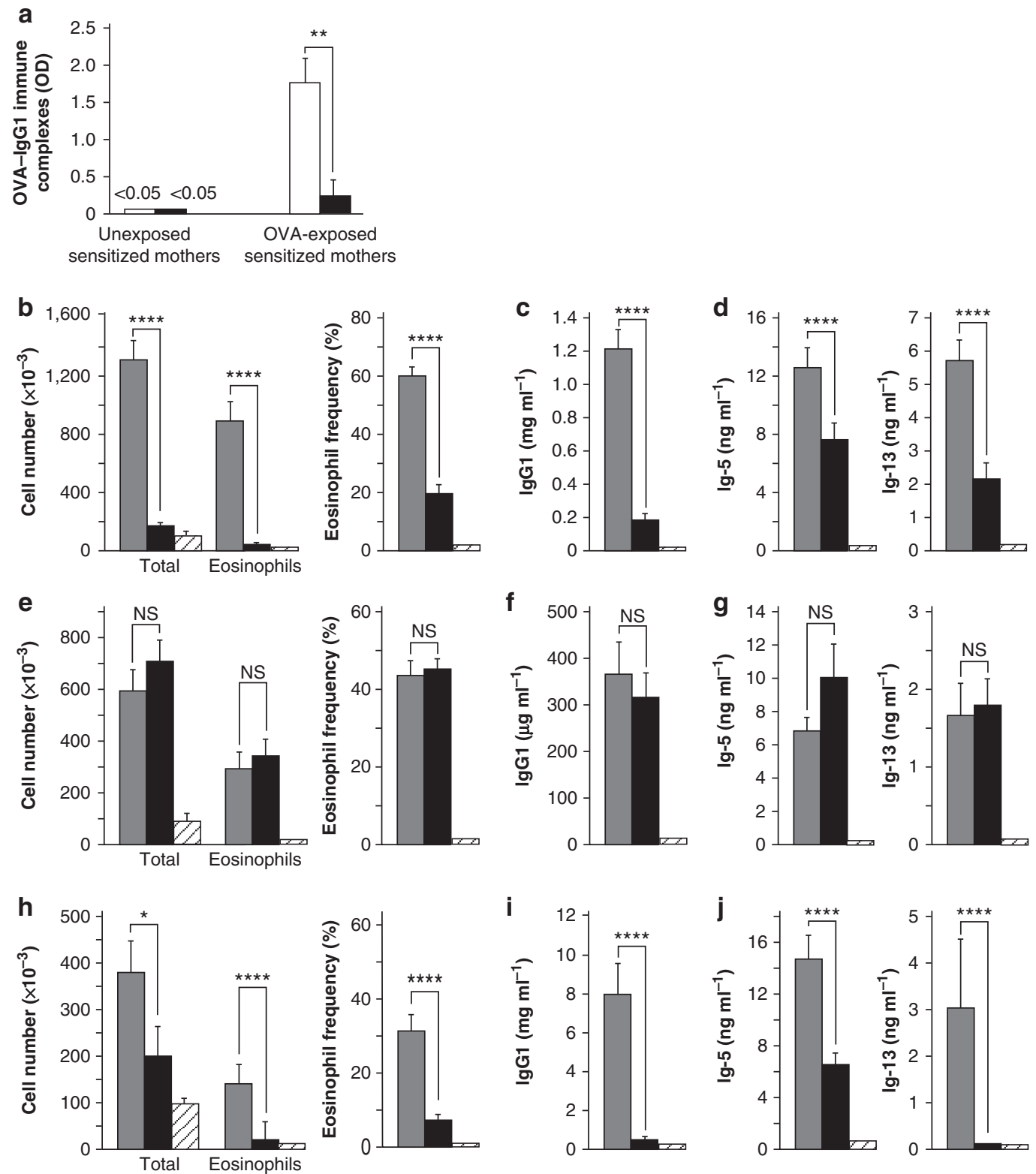

Figure 5 Breastfeeding-induced protection by ovalbumin (OVA)-exposed sensitized mothers requires neonatal Fc receptor (FcRn) but not Fc $\gamma$ RIIb. (a) Levels of OVA-IgG1 immune complexes in pups sera. Wild-type (empty bars) or FcRn-deficient (black bars) C57BL/6 pups were breastfed by unexposed or OVA-exposed sensitized mothers and analyzed 14 days after birth for the presence OVA-IgG1 immune complexes in serum by enzymelinked immunosorbent assay (ELISA). Data show the mean \pm S.e.m. of values obtained in one representative experiments with $n=6$ mice per group. Wild type (b-d), FcRn-deficient (e-g), or Fc $\gamma$ Rllb-deficient ( $\mathbf{h}-\mathbf{j})$ C57BL/6 pups were breastfed by unexposed (dark gray bars) or OVA-exposed (black bars) sensitized mothers. Non-sensitized mice challenged with OVA were used as controls (hatched bars). Data show cell number and eosinophils frequency in bronchoalveolar lavage (BAL) fluids (b, e, and $\mathbf{h}$ ), serum levels of OVA-specific IgG (c, $\mathbf{f}$, and $\mathbf{i})$, and levels of IL-5 and IL-13 secreted by lung cells when incubated with OVA (d, $\mathbf{g}$, and $\mathbf{j})$. Data are expressed as mean \pm s.e.m. of five experiments for wild-type C57BL/6 and two experiments for FcRn-deficient and Fc $\gamma$ RIIB-deficient mice with $n=6-8$ mice per group in each experiment. ${ }^{\star * \star *} P<0.0001 ;{ }^{*} P<0.05 ;$ NS, $P>0.05$.

unexposed sensitized mothers. Similar to wt C57Bl/6 (Figure $\mathbf{5 b}-\mathbf{d})$, Fc $\gamma$ RIIb-deficient mice breastfed by OVA-exposed sensitized mothers were protected from allergic airway disease as shown by reduced airway eosinophilia, serum levels of OVA-specific IgG1, and IL-5 and IL-13 lung secretion (Figure $5 \mathbf{h}-\mathbf{j}$ ). Therefore, breastfeeding-induced protection by OVA-exposed sensitized mothers is independent of the inhibitory Fc $\gamma$ RIIb.
$\mathrm{CD25}+\mathrm{CD} 4{ }^{+} \mathrm{T}_{\text {reg }}$ cells are induced by OVA-IgG immune complexes and are necessary for protection from allergic airway disease upon breastfeeding by OVA-exposed sensitized mothers

Because FcRn was required for both tolerance induction by OVA-exposed sensitized mothers and the transfer of immune complexes from mother's milk to their pups, we next assessed whether milk-borne OVA-IgG immune complexes could induce 


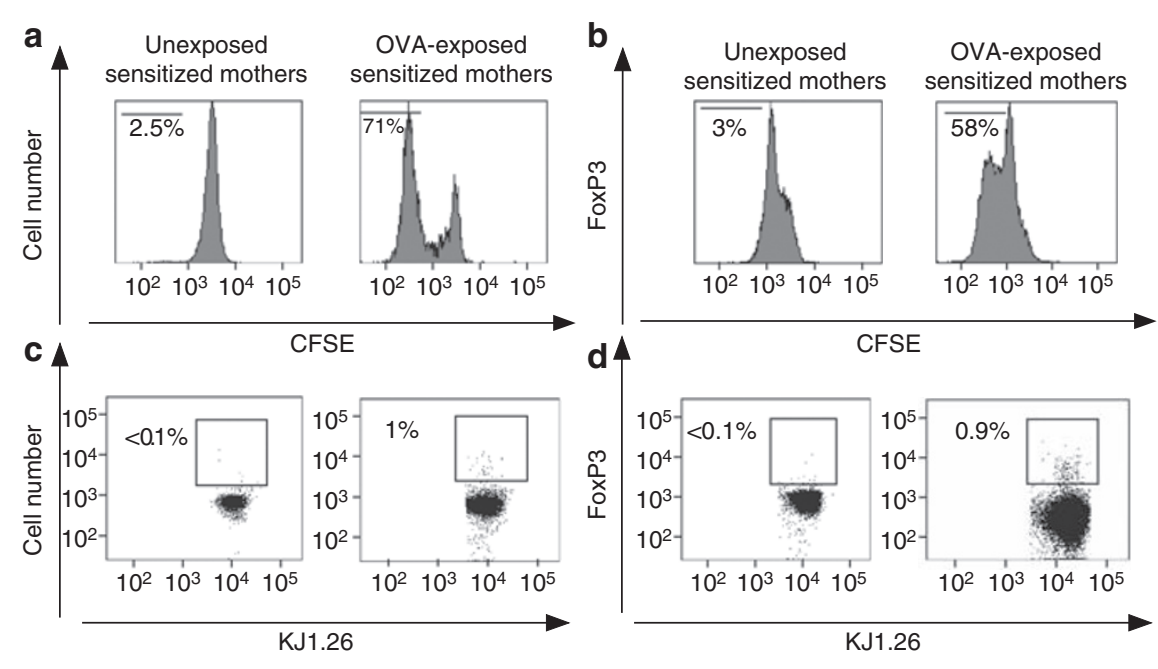

Figure 6 In vitro induction of ovalbumin (OVA)-specific FoxP3 ${ }^{+} \mathrm{T}_{\text {reg }}$ by milk-borne immune complexes. The milk from OVA-exposed or unexposed sensitized mice was harvested and either used immediately or fractionated on FPLC. Unfractionated milk (a and c) or the 500-2,000 kDa milk fraction (b and d) was incubated with bone marrow-derived dendritic cells and CFSE-labeled CD4 ${ }^{+} \mathrm{T}$ cells from DO11.10 T-cell receptor (TCR) transgenic RAG-2-deficient mice. Cells were harvested 5 days later and analyzed by FACS after staining with anti-CD3, anti-FoxP3, and KJ1.26 monoclonal antibodies (mAbs). Data show representative FACS profiles of one experiment out of four. The numbers indicate the frequency of cells that have progressed through the cell cycle (a and $\mathbf{b})$ and the frequency of FoxP3 ${ }^{+}$cells among KJ1.26 ${ }^{+} \mathrm{CD}^{+}$cells $(\mathbf{c}$ and $\mathbf{d})$.

the proliferation of OVA-specific T lymphocytes and their differentiation into FoxP3 ${ }^{+} \mathrm{T}_{\text {reg }}$ cells. We first incubated bone marrow-derived dendritic cells with milk from OVA-exposed or unexposed sensitized mothers and OVA-specific T-cell receptor (TCR) transgenic DO11.10 CD4 ${ }^{+} \mathrm{T}$ cells. We found that $71 \%$ of $\mathrm{T}$ cells had divided upon incubation with milk from OVAexposed sensitized mothers, whereas no proliferation occurred in the presence of milk from unexposed mothers (Figure 6a). Furthermore, milk from OVA-exposed, but not from unexposed, mothers induced the differentiation of $\mathrm{FoxP}^{+} \mathrm{T}$ cells $(1 \pm 0.1$ vs. $<0.1 \%)$ (Figure 6c). The $500-2,000 \mathrm{kDa}$ molecular weight milk fractions from OVA-exposed mothers that contained OVA-IgG immune complexes also induced T-cell proliferation and $\mathrm{T}_{\text {reg }}$ differentiation whereas the corresponding fractions from unexposed mothers did not (Figure $\mathbf{6 b}$ and $\mathbf{d}$ ). Therefore, OVA-IgG immune complexes readily induced the proliferation of OVA-specific $\mathrm{T}$ cell and their differentiation into FoxP3 $^{+} \mathrm{T}$ cells.

We next assessed whether the transfer of milk-borne OVA-IgG immune complexes to the pup could induce the generation of OVA-specific $\mathrm{T}_{\text {reg }}$ cells in vivo. Therefore, we injected 1-day-old $\mathrm{BALB} / \mathrm{c}$ newborns with $\mathrm{CD} 4^{+} \mathrm{T}$ cells purified from the spleens of OVA-specific DO11.10 TCR transgenic RAG-2-deficient neonates. Injected mice were then breastfed by OVA-exposed or unexposed sensitized mothers. Ten days after weaning, the presence of TCR transgenic $\mathrm{CD} 4{ }^{+} \mathrm{T}$ cells was assessed in peripheral and mesenteric lymph nodes and in spleen using the clonotypic mAb KJ1.26. Although the frequency of TCR transgenic $\mathrm{CD}^{+}{ }^{+} \mathrm{T}$ lymphocytes in the peripheral lymph node and the spleen of mice breastfed by OVA-exposed and unexposed sensitized mothers was below $0.2 \%$ (data not shown), it reached $1.3 \%$ in the mesenteric lymph nodes of mice breastfed by OVA-exposed sensitized mothers as compared to $0.2 \%$ in those breastfed by unexposed sensitized mothers (Figure 7a).
Furthermore, the frequencies of $\mathrm{KJ} 1.26^{+} \mathrm{TCR}$ transgenic $\mathrm{CD} 4^{+}$ T cells that were FoxP3 ${ }^{+}$or $\mathrm{CD} 25^{+}$were 2 - to 3 -fold higher in mice breastfed by OVA-exposed sensitized mothers than in those breastfed by unexposed sensitized mothers (Figure $7 \mathbf{b}$ and $\mathbf{c}$ ). In contrast, the frequencies of endogenous $\mathrm{KJ} 1.26^{-} \mathrm{CD} 4^{+} \mathrm{T}$ cells that were FoxP $3^{+}$or $\mathrm{CD} 25^{+}$were similar in both groups. These data indicate the preferential expansion of OVA-specific CD4 T lymphocytes in mice breastfed by OVA-exposed sensitized mothers and their conversion to a regulatory phenotype.

We next injected OVA-specific OTII TCR transgenic Ly5.1 ${ }^{+}$ $\mathrm{CD}^{+}{ }^{+} \mathrm{T}$ lymphocytes into either wt or FcRn-deficient C57BL/6 pups. As observed when T cells from DO11.10 transgenic mice were injected into $\mathrm{BALB} / \mathrm{c}$ mice (Figure $7 \mathrm{c}$ ), $\mathrm{T}$ cells from OTII transgenic mice converted to FoxP3 ${ }^{+}$cells in the MLN of wt C57BL/6 mice breastfed by OVA-exposed sensitized mice (Figure 7d). In contrast, OTII cells were not induced to express FoxP3 when injected into FcRn-deficient mice (Figure 7d). Therefore, the ability of milk-borne OVA-IgG immune complexes to induce $\mathrm{T}_{\text {reg }}$ differentiation was FcRn dependent.

To further show the role of CD25 ${ }^{+} \mathrm{T}$ cells in breastfeedinginduced protection by OVA-exposed sensitized mothers, we injected mice breastfed by OVA-exposed or unexposed sensitized mothers before OVA sensitization with anti-CD25 mAb. As observed in other asthma models, ${ }^{36}$ this treatment resulted in increased allergic airway inflammation in mice breastfed by unexposed sensitized mothers (Figure 8a-c). The levels of inhibition of allergic airway inflammation induced by OVA-exposed sensitized mothers were reduced in mice treated by anti-CD25 $\mathrm{mAb}$ as compared to those treated by rat IgG1: $27 \mathrm{vs.} 88 \%$ inhibition for eosinophilia; 83 vs. $98 \%$ inhibition for OVA-specific IgE, 18 vs. $70 \%$ for lung IL-5 secretion, and 36 vs. $80 \%$ for lung IL-13 secretion (Figure 8a-c). Thus, $\mathrm{CD} 25^{+} \mathrm{CD} 4{ }^{+} \mathrm{T}_{\text {reg }}$ cells are involved in breastfeeding-induced protection induced by OVA-exposed sensitized mothers. 
a
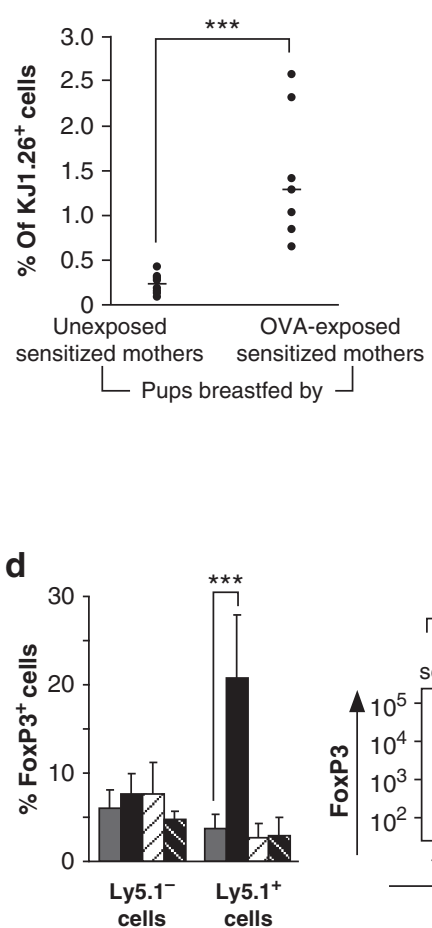

b
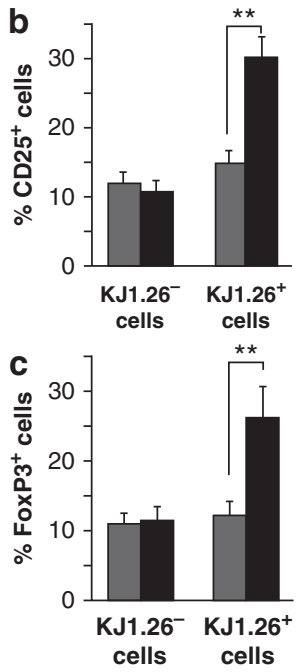

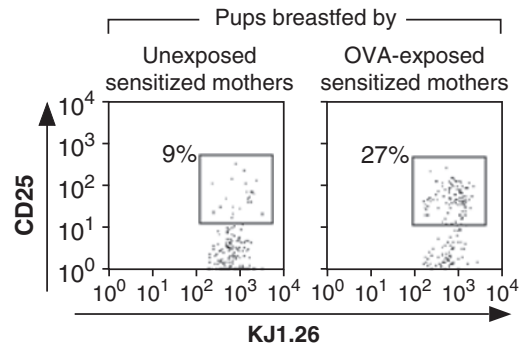

Pups breastfed by

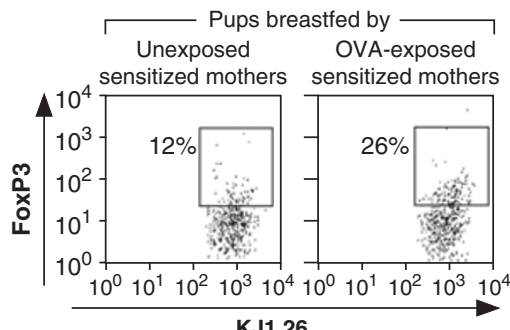

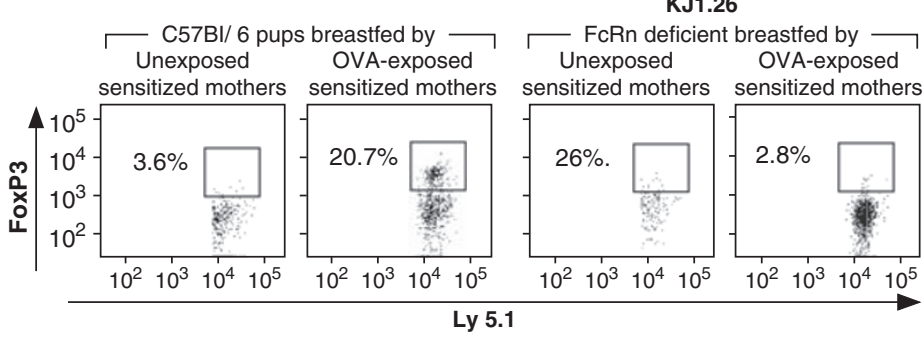

Figure 7 In vivo induction of ovalbumin (OVA)-specific FoxP3 ${ }^{+} \mathrm{T}_{\text {reg }}$ by milk from OVA-exposed sensitized mothers. CD4 ${ }^{+}$cells from RAG-2-deficient DO11.10 (a-c) or Ly5.1 + OTII (d) TCR transgenic mice were injected into 1-day-old BALB/c (a-c) or wild-type or FcRn-deficient C57BL/6 pups (d). Mice were breastfed by unexposed or OVA-exposed sensitized mothers and mesenteric lymph nodes cells were harvested 10 days after weaning and analyzed by FACS. (a) Frequency of transferred OVA-specific T-cell receptor (TCR) transgenic T cells in BALB/c pups. Data show the frequency of $\mathrm{KJ} 1.26^{+}$cells among CD4 ${ }^{+} \mathrm{T}$ cells in individual mice (filled circles). The bars indicate the median values in one representative out of three experiments. (b and c) Cells from mice breastfed by unexposed or OVA-exposed sensitized mothers were analyzed by FACS. (b) CD25 expression. Data show the frequency of $\mathrm{CD} 25^{+}$cells among KJ1.26- and KJ1.26+ $\mathrm{CD} 4^{+}$cells in mice breastfed by unexposed (gray bars) and OVA-exposed (black bars) sensitized mothers (left panel) and representative FACS profiles (right panel). Data are expressed as mean \pm s.e.m. of one experiment out of three with $n=6-8$ mice per group in each experiment. (c) FoxP3 expression. Data show the frequency of FoxP3 ${ }^{+}$cells among KJ1.26- and KJ1.26 ${ }^{+} \mathrm{CD}^{-}{ }^{+}$cells in mice breastfed by unexposed (gray bars) and OVA-exposed (black bars) sensitized mothers (left panel), and representative FACS profiles (right panel). Data are expressed as mean \pm s.e.m. of one experiment out of three with $n=6-8$ mice per group in each experiment. (d) FoxP3 expression in wild-type or FcRn-deficient C57BL/6 pups. Data show the frequency of FoxP3 ${ }^{+}$cells among Ly5.1- cells and donor Ly5.1 ${ }^{+}$cells in wild-type mice breastfed by unexposed (gray bars) or OVA-exposed (black bars) sensitized mothers and in FcRn-deficient mice breastfed by unexposed (dashed white bars) or OVA-exposed (dashed black bars) sensitized mothers (upper panel) and representative FACS profiles (lower panel). Data are expressed as mean \pm s.e.m. of one experiment out of two with $n=6-8$ mice per group in each experiment. ${ }^{\star \star \star} P<0.001 ;{ }^{* \star} P<0.01$.

\section{DISCUSSION}

In this study, we observed that breastfeeding by antigen-exposed sensitized mothers abolished asthma development in the progeny. In contrast to the protection afforded by antigen-exposed non-sensitized mothers, protection conferred by sensitized mothers was much more profound, long lasting, did not require the presence of TGF- $\beta$ in milk, and relied on the development of $\mathrm{CD} 25^{+} \mathrm{CD} 4^{+} \mathrm{T}_{\text {reg }}$ cells.

Breastfeeding-induced inhibition of $\mathrm{Th} 2 \mathrm{immune}$ responses in rodents fostered by antigen-sensitized mothers has been extensively studied. ${ }^{5,22-28,37}$ It was proposed that this phenomenon was dependent on the induction of antigen-specific IgG following maternal immunization and their transfer to the neonates through breast milk. Proposed mechanisms included interference with the neonatal idiotypic network, masking of antigenic determinants, formation of immune complexes at the time of antigen sensitization leading to antigen clearance, and engagement of the inhibitory receptor Fc $\gamma$ RIIB on B lymphocytes or
DCs. ${ }^{22,24-27}$ In most studies, protection lasted less than 6 weeks and vanished when maternal IgG were cleared. ${ }^{24,26}$ In contrast with these studies, we have observed that mice breastfed by OVA-exposed sensitized mothers remained protected after OVA-specific IgG had disappeared from circulation. Instead of being directly responsible for tolerance induction, our data suggest that IgG induce active and profound antigen-specific tolerance in the breastfed pup through the generation of milk immune complexes.

How could milk immune complexes induce tolerance in the breastfed pups? Thirty years ago, an elegant study reported that in vitro-made antigen-IgG complexes were transferred much more efficiently across the epithelial barrier of neonatal rats than free antigen. ${ }^{38}$ The antigen was found in coated vesicles in epithelial cells and transferred to extracellular spaces only in the presence of antigen-specific IgG. Further studies showed that antigen transfer required the Fc portion of IgG. Accordingly, neonatal oral tolerance could be induced to human $\operatorname{IgG}$ that 

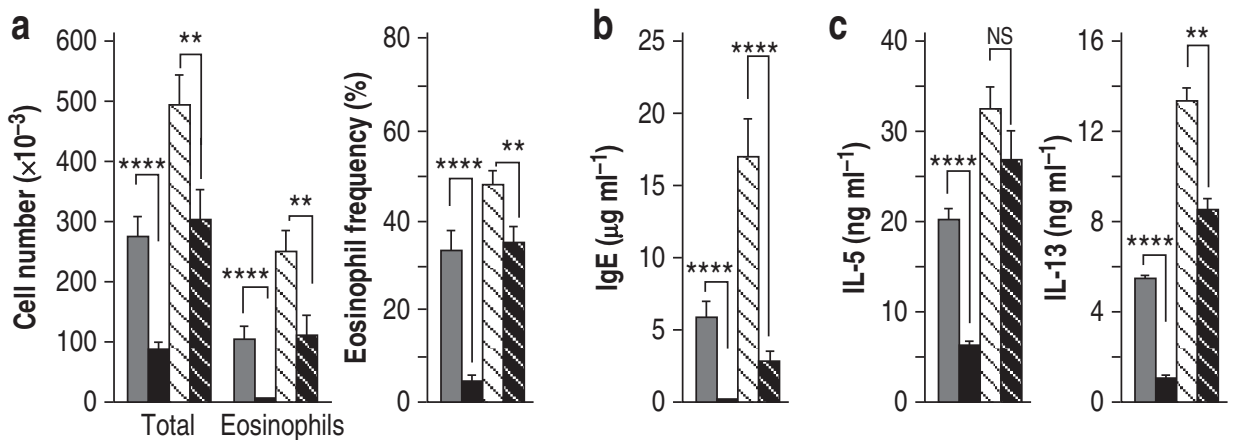

Figure 8 Breastfeeding-induced tolerance in anti-CD25 monoclonal antibody (mAb)-treated mice. BALB/c pups were breastfed by unexposed or ovalbumin (OVA)-exposed sensitized mothers. When 6-week-old, the offspring were treated with anti-CD25 or isotypic control mAb, sensitized with OVA 1 week later, and challenged with OVA aerosols. Data show the total number of cells and frequency of eosinophils in bronchoalveolar lavage (BAL) fluid (a), serum levels of OVA-specific IgE content (b), and levels of IL-5 and IL-13 secreted by lung cells when incubated with OVA (c) in mice breastfed by unexposed (gray bars) or OVA-exposed (black bars) sensitized mothers treated with an isotypic control mAb, and unexposed (dashed white bars) or OVA-exposed (dashed black bars) sensitized mothers treated with an anti-CD25 mAb. Data are expressed as mean \pm s.e.m. of two experiments with $n=6-8$ mice per group in each experiment ${ }^{* \star \star *} P<0.0001 ;{ }^{* \star \star} P<0.001 ;{ }^{\star \star} P<0.01$

were efficiently transferred across the epithelial barrier, but not to OVA that is not. ${ }^{39}$ Other studies identified FcRn as the receptor allowing an active and nondegradative transfer of IgG across the proximal small intestine..$^{29,30,40}$ Here, we observed that milk-borne OVA-IgG complexes were actively transferred from the mother to the pup through the FcRn. Furthermore, the FcRn-mediated transfer of OVA-IgG complexes resulted in the induction of FoxP $3^{+} \mathrm{T}_{\text {reg }}$ and FcRn-deficient mice breastfed by OVA-exposed sensitized mice were not protected from allergic airway disease. Altogether, our data show that milk-borne antigen-IgG immune complexes were efficiently transferred to the breastfed pup through the FcRn and, most importantly, that this phenomenon resulted in the induction of active tolerance.

Immune complexes can lead to severe inflammation and tissue damage as observed in erythematous lupus or poststreptococcal glomerulonephritis. In other settings, immune complexes can also suppress immune responses. This was shown both in mice ${ }^{41-43}$ and in humans. ${ }^{44,45}$ Saint-Remy and his colleagues showed some years ago that patients suffering from allergic bronchial asthma to Dermatophagoides could be efficiently treated by inoculation of allergen-IgG immune complexes. ${ }^{44}$ We have observed that the transfer of OVA-IgG immune complexes from the mother to the neonate resulted in the expansion of OVA-specific $\mathrm{T}_{\text {reg }}$ cells and protection from allergic airway disease. The exposition of newborns to immune complexes through the gut is likely to be important in this process as the gut-associated lymphoid tissues are specialized in tolerance induction. ${ }^{46,47}$ Surprisingly, we have found that the inhibitory receptor Fc $\gamma$ RIIB that is involved in both B- and T-cell tolerance was not necessary for tolerance induction in pups breastfed by OVA-exposed sensitized mothers. The ability of milk immune complexes to induce tolerance and not inflammation may also rely on their biochemical characteristics. Thus, we found that milk-borne OVA-IgG immune complexes induced the differentiation of naive OVA-specific $\mathrm{T}$ cells into FoxP3 ${ }^{+} \mathrm{T}_{\text {reg }}$ in vitro. Immune complexes formed in the excess of antibody are immunosuppressive whereas they are immunogenic when the antigen is in excess. ${ }^{42}$ In the case of immune complexes found in the milk of OVA-exposed sensitized mothers, antibodies are in large excess as OVA-specific IgG1 levels are in the range of $100 \mu \mathrm{g} \mathrm{ml}^{-1}$ and OVA levels in the range of $100 \mathrm{ng} \mathrm{ml}^{-1}$. Other biochemical characteristics such as antibody glycosylation have an impact on antibody activity in vivo. ${ }^{48}$ The presence of galactose and sialic acid is associated with anti-inflammatory properties of antibody. It remains to be determined whether milk immune complexes contain galactose and sialic acid and, if this is the case, whether they confer to these molecules immunosuppressive properties.

The increased protection afforded by milk OVA-Ig immune complexes as compared to free OVA may also result from a more efficient antigen presentation by tolerogenic antigen-presenting cell. Indeed, Fc $\gamma$-mediated or complement receptor-mediated presentation of antigen is much more efficient than passive pinocytosis. ${ }^{48,49}$ Accordingly, when normalized to OVA concentration, milk OVA-IgG immune complexes were at least 100fold more efficient than free OVA at inducing the proliferation of OVA-specific TCR transgenic T cells in vitro (Figure 6 and Supplementary Figure 3). Accordingly, the role of other Fc $\gamma$ R than Fc $\gamma$ RIIb and complement receptor such as $\mathrm{Clq}$ remains to be determined in tolerance induction after transfer of immune complexes from mother to the pups. In addition to its critical role in the transport of immune complexes from the gut lumen to the intestinal mucosa, the FcRn may also enhance the presentation of Ag-Ig immune complexes by DCs, possibly by directing multimeric immune complexes to lysosomes. ${ }^{50}$

Adoptive transfer experiments showed that naive antigenspecific newborn $\mathrm{CD} 4^{+} \mathrm{T}$ cells differentiated into FoxP3 ${ }^{+}$ $\mathrm{CD} 25^{+} \mathrm{T}_{\text {reg }}$ cells in mice breastfed by OVA-exposed sensitized mothers. Furthermore, protection afforded by OVA-exposed sensitized mothers was reduced, although not totally abolished, upon treatment with anti-CD25 mAb showing a role for FoxP3 ${ }^{+} \mathrm{CD} 25^{+} \mathrm{T}_{\text {reg }}$ in neonatal tolerance induction upon transfer of milk immune complexes to the neonates. IL-10secreting $\operatorname{Tr} 1$ lymphocytes might also have a role in tolerance induced in mice breastfed by OVA-exposed sensitized mothers as $\operatorname{Tr} 1$ were shown to be enriched in the gut. ${ }^{51}$ However, 
our preliminary data showed that IL-10-deficient mice are equally protected upon breastfeeding by OVA-exposed sensitized mothers.

The presence of IgA in human breast milk is well documented. Maternal pathogen-specific IgA in breast milk are crucial to prevent respiratory and gut infections in the breastfed child. ${ }^{7}$ IgA have also been associated with tolerance induction in both mice and humans. ${ }^{17-20}$ Here, we have observed that milk IgA were not necessary for tolerance induction. The role of IgG in human milk has been much less studied and furthermore, no study has investigated whether breast milk contains IgG immune complexes and if it does, how could these complexes influence the development of the newborn immune system. Feld $1-\mathrm{IgG}^{52}$ immune complexes have been found in maternal sera and cord blood, suggesting that allergens-IgG immune complexes might also be found in human milk. Because FcRn is expressed in the human intestine, it is possible that what we have observed in mice could be relevant in humans. This issue could possibly be addressed by performing clinical trials aimed at assessing if there is a correlation between the presence of airborne allergen in breast milk, its presence as free antigen or in the form of immune complexes and the development of asthma in the breastfed child. The identification of key parameters for tolerance induction in neonates may allow the elaboration of new guidelines for asthma primary prevention.

In conclusion, we believe that this study provides new insights on the mechanisms of tolerance induction in neonates and highlights that IgG immune complexes found in breast milk are potent inducers of oral tolerance.

\section{METHODS}

Mice. BALB/c mice and C57BL/6 mice were purchased from the Centre d'Elevage Janvier (Le Genest Saint Isle, France) and housed in our animal facility under SPF conditions. RAG-2-deficient mice were obtained from the Centre de Transgénèse et Archivage d'Animaux Modèles (Orleans, France); DO.11.10 and OTII TCR transgenic mice from F. Powrie (Oxford, UK) and B. Malissen (Marseille, France), respectively; Fc $\gamma$ RIIb-deficient mice from S. Verbeek (Leiden University, the Netherlands); and FcRn-deficient mice from D. Roopenian (Jackson laboratory, Bar Harbor, ME).

Sensitization and exposure of mothers to the antigen. For sensitization, 6- to 8-week-old BALB/c mice were sensitized 1 week apart by two consecutive intraperitoneal injections of $10 \mu \mathrm{g}$ of OVA (grade V; Sigma, Saint-Quentin, France) in 2 mg of alum (Pierce, Rockford, IL) (Figure 1a). Non-sensitized and sensitized mice were mated 2 days after the last injection. At delivery, pups from sensitized mothers were replaced by pups from non-sensitized mothers. For antigen exposure, mothers were exposed or not exposed to $0.3 \%$ OVA (grade V; Sigma) aerosols for 20 min every other day starting $24 \mathrm{~h}$ after delivery until weaning using an ultrasonic nebulizer (Ultramed; Medicalia) connected to a $13,000 \mathrm{~cm}^{3}$ box that served as the deposition chamber for the mice. Aerosols were given in groups of a maximum of 5-10 mothers. During aerosol exposure, mothers were separated from their progeny. OVAspecific IgE and IgG1 were readily detected in the serum of OVA-sensitized mothers and their levels increased 2- to 3-fold upon exposure to OVA aerosols (Supplementary Figure 1). In addition, OVA-exposed sensitized mothers exhibited mild eosinophilic airway inflammation (Supplementary Figure 1). Where indicated, mothers were treated with $1 \mathrm{mg}$ of anti-TGF- $\beta$ antibody (1D11 clone; ATCC, Manassas, VA) or isotypic control rat IgG1 (GL113; DNAX, Palo Alto, CA) twice a week or $100 \mu \mathrm{g}$ of anti-CCL-28 antibody (clone 134306; R\&D Systems, Minneapolis, MN) ${ }^{21}$ or isotypic ctrl rat IgG2b (clone 141945; R\&D Systems) every other day from delivery until weaning. After treatment with antibody to TGF- $\beta$, the TGF- $\beta 1$ content in milk was reduced at least sixfold ( $1.4 \pm 0.3$ to $0.2 \pm 0.1 \mathrm{ng} \mathrm{ml}^{-1}$; mean of four experiments \pm s.d.).

Induction of allergic asthma in the progeny. Breastfed mice were sensitized at the age of 6-8 weeks unless stated otherwise (Figure 1a). Sensitization was performed by two intraperitoneal injections of $10 \mu \mathrm{g}$ of OVA in $2 \mathrm{mg}$ of alum (Pierce) at day 0 and 7 . Mice were exposed daily to $0.3 \%$ OVA aerosols for 5 days starting 10 days after the second injection. Aerosol exposure was performed for 20 min using an ultrasonic nebulizer (Ultramed; Medicalia) connected to a $13,000 \mathrm{~cm}^{3}$ box that served as the deposition chamber for the mice. When indicated, mice were injected with $0.5 \mathrm{mg}$ of anti-CD25 mAb (PC61 clone; ATCC) or with rat IgG1 (GL113 clone; DNAX) 1 week before sensitization. In some experiments, mice were sensitized with $10 \mu \mathrm{g}$ LACK in $2 \mathrm{mg}$ of alum and further exposed to $0.2 \%$ LACK aerosols as described. ${ }^{16}$ LACK was detoxified using an EndoTrap column (Profos, Regensburg, Germany) according to the manufacturer's instructions. Lipopolysaccharide levels were below $10 \mathrm{ng}$ per $\mathrm{mg}$ of protein.

Airway hyperreactivity. Airway hyperreactivity was measured 1 day after the last aerosol by invasive plethysmography (emka Technologies, Paris, France) in response to inhaled methacholine (Sigma). For dynamic lung resistance and compliance, measurements were performed using a flexiVent apparatus (SCIREQ, Montreal, Canada). Mice were anesthetized $\left(5 \mathrm{ml}\right.$ per $\mathrm{kg}$ body weight $\left(\mathrm{ml} \mathrm{kg}^{-1}\right)$ of 10 $\%$ medetomidine (Pfizer, Paris, France) and 10\% ketamine (Merial, Lyon, France)), tracheotomized, paralyzed $\left(5 \mathrm{ml} \mathrm{kg}^{-1}\right.$ of $1 \%$ pancuronium bromide (Organon, Puteaux, France)) and immediately intubated with an 18-gauge catheter, followed by mechanical ventilation. Respiratory frequency was set at 150 breaths per min with a tidal volume of $0.2 \mathrm{ml}$, and a positive-end expiratory pressure of $2 \mathrm{ml} \mathrm{H}_{2} \mathrm{O}$ was applied. Increasing concentrations of methacholine $\left(0-24 \mathrm{mg} \mathrm{ml}^{-1}\right)$ were administered at the rate of 20 puffs per $10 \mathrm{~s}$, with each puff of aerosol delivery lasting $10 \mathrm{~ms}$, through a nebulizer aerosol system with a $2.5-4 \mu \mathrm{m}$ aerosol particle size generated by a nebulizer head (Aeroneb; Aerogen, Dangan, Ireland). Baseline resistance was restored before administering the subsequent doses of methacholine.

Analysis of cells in BAL fluids. Mice were bled and a canula was inserted into the trachea. Lungs were washed three times with $1 \mathrm{ml}$ of phosphatebuffered saline (PBS). For differential BAL cell counts, cells were stained with anti-CCR3 (R\&D Systems), anti-Gr1 (BD, Le Pont de Claix, France), anti-CD3 (BD), and anti-CD19 (BD) antibodies and analyzed by flow cytometry using a FACScalibur flow cytometer and CellQuest software (BD). Eosinophils were defined as CCR3 ${ }^{+} \mathrm{CD}^{-}{ }^{-} \mathrm{CD} 19^{-}$, neutrophils as $\mathrm{Gr}-1^{\text {high }} \mathrm{CD} 3^{-} \mathrm{CD} 19^{-}$, lymphocytes as $\mathrm{CD} 3^{+} \mathrm{CD} 19^{+}$, and alveolar macrophages as large autofluorescent cells.

Serum and milk. Blood was harvested from mice by intracardiac puncture and serum was prepared by centrifugation $(10,000 \mathrm{~g}, 10 \mathrm{~min})$ using heparin-treated tubes (SARSTEDT, Marnay, France). Breast milk was collected from the stomach of 2-week-old pups 4-6h after OVA aerosol exposure of lactating mothers and diluted in 1 volume of PBS. Samples were spun down at $10,000 \mathrm{~g}$ for $10 \mathrm{~min}$ and the supernatant was collected and stored at $-20^{\circ} \mathrm{C}$ until analysis.

Antibody levels. Serum and milk were analyzed for the presence of OVA-specific or LACK-specific IgA, IgE, IgG1, and IgG2a by ELISA. For IgG1, MaxiSorp plates (Nunc, Roskilde, Denmark) were coated with OVA or LACK, saturated with $10 \%$ fetal calf serum in PBS, and incubated with serial dilution of sera followed by biotinylated anti-IgG1 antibody (BD553-441; BD). For antigen-specific IgA, IgE and IgG2a plates were first coated with their respective capture $\mathrm{mAb}(\mathrm{BD})$, saturated with 
$10 \%$ fetal calf serum in PBS, and incubated with serial dilution of sera serum dilutions followed by biotin-conjugated OVA or LACK antigen. Horseradish peroxidase-conjugated streptavidin (BD) and tetramethylbenzidine (KPL, Gaithersburg, MD) were used for detection.

OVA levels in milk. Milk was analyzed for the presence of OVA by ELISA or western blot analysis. For ELISA, MaxiSorp plates (Nunc) were coated with a rabbit anti-OVA polyclonal antibody (AB1221; Abcam, Paris, France), saturated with 3\% dry milk in PBS-Tween 0.05\%, and incubated with serial dilution of milk followed by a biotin-conjugated anti-OVA polyclonal antibody (AB8389; Abcam). Horseradish peroxidase-conjugated streptavidin (BD) and tetramethylbenzidine (KPL) were used for detection. For western blot analysis, the samples were analyzed by SDS-polyacrylamide gel electrophoresis onto a $10 \%$ acrylamide gel and transferred onto a nitrocellulose membrane. OVA was detected using a mouse anti-OVA mAb (AB17201; Abcam), followed by a goat anti-mouse IgG1 horseradish peroxidase-conjugated antibody (Jackson ImmunoResearch, Suffolk, UK). The signals were revealed using SuperSignal West Femto Kit (Pierce) and chemiluminescence was recorded using a luminescence image analyzer LAS-3000 (Raytest, La Defense, France). Quantification of captured images was performed using the Multi Gauge software (Fujifilm, Bois D'arcy, France).

Immune complexes content in milk and serum. Milk and serum were analyzed for the presence of OVA-IgG1 immune complexes by ELISA. MaxiSorp plates were coated with a rabbit anti-OVA polyclonal antibody (AB1221; Abcam), saturated with 3\% fetal calf serum in PBS-Tween $0.05 \%$, and incubated with serial dilutions of milk or serum followed by biotin-conjugated anti-IgG1 antibody (BD553-441; BD). Horseradish peroxidase-conjugated streptavidin (BD) and tetramethylbenzidine (KPL) were used for detection. For western blot anlysis, milk samples were incubated or not incubated with protein $G$ sepharose beads during $1 \mathrm{~h}$ (GE-Healthcare, Villeneuve Coubet, France). Samples were spun down $(1,500 \mathrm{~g}, 10 \mathrm{~min})$, and supernatants and column eluates were analyzed by SDS-polyacrylamide gel electrophoresis onto a $10 \%$ acrylamide gel followed by standard immunoblotting techniques as described above. For milk fractionation, milk samples were loaded onto a Superdex 200 column (Pharmacia, Saint-Quentin Yvelines, France) and $0.5 \mathrm{ml}$ fractions were collected. Levels of OVA-IgG immune complexes and OVA-specific IgG were analyzed by ELISA in FPLC fractionated milk.

Cytokine assays. Lungs were harvested, minced, and digested with collagenase I (Gibco, Cergy-Pontoise, France) and DNAse (Roche, Neuilly sur Seine, France) for $30 \mathrm{~min}$ at $37^{\circ} \mathrm{C}$. Cell suspensions were filtered through a $70 \mu \mathrm{m}$ cell strainer and depleted of red blood cells using red blood cell lysis buffer. Cells from each group were pooled and $4 \times 10^{6}$ lung cells were cultured for $72 \mathrm{~h}$ in medium containing or not containing OVA $\left(100 \mu \mathrm{g} \mathrm{ml}^{-1}\right)$ in 48 -well plates. Culture medium was RPMI-1640 (Gibco) containing $10 \%$ heat-inactivated fetal calf serum (Perbio, Brebiéres, France), $50 \mu \mathrm{M} \beta 2$-mercaptoethanol (Gibco), and penicillin/streptomycin (Gibco). Supernatants were analyzed for IL-4, IL-5, IL-10, and IL-13 contents by ELISA using antibody pairs from BD (IL-4, IL-5, IL-10) or from $\mathrm{R} \& \mathrm{D}$ Systems (IL-13). The lower limits of detection were $15 \mathrm{pg} \mathrm{ml}^{-1}$ for IL-4, $300 \mathrm{pg} \mathrm{ml}^{-1}$ for IL-5, and $150 \mathrm{pg} \mathrm{ml}^{-1}$ for IL-10 and IL-13.

Histology. Left lungs were harvested and fixed with Immunohistofix and embedded in Immunohistowax (Aphase, Mormont, Belgium). Sections $(4 \mu \mathrm{m})$ were prepared and stained with May-Grünwald Giemsa (Sigma) or Periodic Acid Schiff (Sigma).

T-cell proliferation in vitro. Splenocytes from adults DO11.10 TCR transgenic RAG-2-deficient mice were prepared and $\mathrm{CD} 4^{+} \mathrm{T}$ cells were purified by positive selection using the $\mathrm{CD} 4^{+} \mathrm{T}$ cells isolation kit (Miltenyi Biotec, Paris, France). DCs were generated from bone marrow cells from $\mathrm{BALB} / \mathrm{c}$ mice in Iscove's modified Dulbecco's medium supplemented with granulocyte macrophage-colony-stimulating factor from J558 cells culture supernatant $(20 \%) .{ }^{53} \mathrm{~T}$ cells $\left(2 \times 10^{5}\right)$ were stained with $1 \mu \mathrm{M}$ CFSE and incubated with $2 \times 10^{4}$ DCs in the presence of graded concentrations of OVA, 10 times diluted milk from sensitized or non-sensitized mothers exposed or not exposed to OVA, or with immune complexes-containing fractions obtained after breast milk gel filtration and concentration. Cells were harvested 5 days later and analyzed by flow cytometry upon surface staining with anti-CD3, anti-KJ1.26 mAb (BD). Cells were then fixed, permeabilized using the Fixation and Permeabilization Kit (eBioscience, San Diego, CA), and stained with anti-FoxP3 mAb (eBioscience).

T-cell adoptive transfer. Splenocytes from 5-day-old DO11.10 TCR transgenic RAG-2-deficient mice or from OTII TCR transgenic Ly5.1 ${ }^{+/-}$ mice were prepared and $\mathrm{CD} 4^{+} \mathrm{T}$ cells were purified by positive selection using the $\mathrm{CD}^{+}{ }^{+} \mathrm{T}$ cells isolation kit (Miltenyi Biotec). Purity was above $98 \%$. Purified cells $\left(5 \times 10^{5}\right.$ per mouse) were injected intravenously into 1 day-old BALB/c pups or into wt or FcRn-deficient C57BL/ 6 that were then breastfed by sensitized mothers exposed or not exposed to OVA. Spleen, mesenteric, and peripheral lymph node were harvested 1 week after weaning and cells were analyzed by flow cytometry upon staining with antiCD4, anti-CD25, anti-KJ1.26 mAb for DO11.10 CD4 T-cell detection or with anti-Ly5.1 mAb for OTII CD4 T cells detection (BD). Cells were then fixed, permeabilized using the Fixation and Permeabilization Kit (eBioscience), and stained with anti-FoxP3 mAb (eBioscience).

Statistical analysis. Statistical significance was assessed using a two-tail $P$-value calculated with Mann-Whitney nonparametric test.

SUPPLEMENTARY MATERIAL is linked to the online version of the paper at http://www.nature.com/mi

\section{ACKNOWLEDGMENTS}

We thank Veronique Thieffin, Alain Barbot, and Nicolas Guy for animal technical assistance; Joelle Bigay for FPLC technical assistance; and Frank Aguila for assistance with the figures. This work was supported by grants from the Agence Nationale de la Recherche (SEST), the Fondation pour la Recherche Medicale (FRM) and DC-THERA Network.

\section{DISCLOSURE}

The authors declared no conflict of interest.

2010 Society for Mucosal Immunology

\section{REFERENCES}

1. Adkins, B., Leclerc, C. \& Marshall-Clarke, S. Neonatal adaptive immunity comes of age. Nat. Rev. Immunol. 4, 553-564 (2004).

2. Bach, J.F. The effect of infections on susceptibility to autoimmune and allergic diseases. N. Engl. J. Med. 347, 911-920 (2002).

3. Masoli, M., Fabian, D., Holt, S. \& Beasley, R. The global burden of asthma: executive summary of the GINA Dissemination Committee report. Allergy 59, 469-478 (2004).

4. Holt, P.G., Macaubas, C., Stumbles, P.A. \& Sly, P.D. The role of allergy in the development of asthma. Nature 402, B12-B17 (1999).

5. Fusaro, A.E. et al. Maternal-fetal interaction: preconception immunization in mice prevents neonatal sensitization induced by allergen exposure during pregnancy and breastfeeding. Immunology 122, 107-115 (2007).

6. Labbok, M.H., Clark, D. \& Goldman, A.S. Breastfeeding: maintaining an irreplaceable immunological resource. Nat. Rev. Immunol. 4, 565-572 (2004).

7. Brandtzaeg, P. Mucosal immunity: integration between mother and the breast-fed infant. Vaccine 21, 3382-3388 (2003).

8. van Odijk, J. et al. Breastfeeding and allergic disease: a multidisciplinary review of the literature (1966-2001) on the mode of early feeding in infancy and its impact on later atopic manifestations. Allergy 58, 833-843 (2003).

9. Greer, F.R., Sicherer, S.H. \& Burks, A.W. Effects of early nutritional interventions on the development of atopic disease in infants and children: the role of maternal dietary restriction, breastfeeding, timing of introduction of complementary foods, and hydrolyzed formulas. Pediatrics 121, 183-191 (2008).

10. Gdalevich, M., Mimouni, D. \& Mimouni, M. Breast-feeding and the risk of bronchial asthma in childhood: a systematic review with meta-analysis of prospective studies. J. Pediatr. 139, 261-266 (2001). 
11. Zeiger, R.S. Food allergen avoidance in the prevention of food allergy in infants and children. Pediatrics 111, 1662-1671 (2003).

12. Kull, I., Almqvist, C., Lilja, G., Pershagen, G. \& Wickman, M. Breastfeeding reduces the risk of asthma during the first 4 years of life. J. Allergy. Clin. Immunol. 114, 755-760 (2004).

13. Scholtens, S. et al. Breast feeding, parental allergy and asthma in children followed for 8 years. The PIAMA birth cohort study. Thorax 64, 604-609 (2009).

14. Sears, M.R. et al. Long-term relation between breastfeeding and development of atopy and asthma in children and young adults: a longitudinal study. Lancet 360, 901-907 (2002).

15. Verhasselt, V. et al. Breast milk-mediated transfer of an antigen induces tolerance and protection from allergic asthma. Nat. Med. 14, 170-175 (2008).

16. Julia, V. et al. A restricted subset of dendritic cells captures airborne antigens and remains able to activate specific $T$ cells long after antigen exposure. Immunity 16, 271-283 (2002).

17. Smits, H.H. et al. Cholera toxin B suppresses allergic inflammation through induction of secretory IgA. Mucosal. Immunol. 2, 331-339 (2009)

18. Favre, L., Spertini, F. \& Corthesy, B. Secretory IgA possesses intrinsic modulatory properties stimulating mucosal and systemic immune responses. J. Immunol. 175, 2793-2800 (2005).

19. Sletten, G.B., Halvorsen, R., Egaas, E. \& Halstensen, T.S. Casein-specific immunoglobulins in cow's milk allergic patient subgroups reveal a shift to IgA dominance in tolerant patients. Pediatr. Allergy Immunol. 18, 71-80 (2007).

20. Pilette, C., Durham, S.R., Vaerman, J.P. \& Sibille, Y. Mucosal immunity in asthma and chronic obstructive pulmonary disease: a role for immunoglobulin A? Proc. Am. Thorac. Soc. 1, 125-135 (2004).

21. Wilson, E. \& Butcher, E.C. CCL28 controls immunoglobulin (Ig)A plasma cell accumulation in the lactating mammary gland and IgA antibody transfer to the neonate. J. Exp. Med. 200, 805-809 (2004).

22. Jarrett, E. \& Hall, E. Selective suppression of IgE antibody responsiveness by maternal influence. Nature 280, 145-147 (1979).

23. Jarrett, E.E. \& Hall, E. IgE suppression by maternal lgG. Immunology 48, 49-58 (1983)

24. Uthoff, H. et al. Critical role of preconceptional immunization for protective and nonpathological specific immunity in murine neonates. J. Immunol. 171, 3485-3492 (2003).

25. Boyle, R.J. \& Tang, M.L. Can allergic diseases be prevented prenatally? Allergy 61, 1423-1431 (2006).

26. Fusaro, A.E. et al. Influence of maternal murine immunization with Dermatophagoides pteronyssinus extract on the type I hypersensitivity response in offspring. Int. Arch. Allergy Immunol. 127, 208-216 (2002).

27. Seeger, M. et al. Antigen-independent suppression of the IgE immune response to bee venom phospholipase A2 by maternally derived monoclonal IgG antibodies. Eur. J. Immunol. 28, 2124-2130 (1998).

28. Matson, A.P., Thrall, R.S., Rafti, E. \& Puddington, L. Breastmilk from allergic mothers can protect offspring from allergic airway inflammation. Breastfeed Med. 4, 167-174 (2009).

29. Roopenian, D.C. \& Akilesh, S. FcRn: the neonatal Fc receptor comes of age. Nat. Rev. Immunol. 7, 715-725 (2007).

30. Qiao, S.W., Lencer, W.I. \& Blumberg, R.S. How the controller is controlled-neonatal Fc receptor expression and immunoglobulin $G$ homeostasis. Immunology 120, 145-147 (2007).

31. Yoshida, M. et al. Human neonatal Fc receptor mediates transport of IgG into luminal secretions for delivery of antigens to mucosal dendritic cells. Immunity 20, 769-783 (2004).

32. Desai, D.D. et al. Fc gamma receptor IIB on dendritic cells enforces peripheral tolerance by inhibiting effector T cell responses. J. Immunol. 178, 6217-6226 (2007).
33. Samsom, J.N. et al. Fc gamma RIIB regulates nasal and oral tolerance: a role for dendritic cells. J. Immunol. 174, 5279-5287 (2005).

34. Siragam, V. et al. Intravenous immunoglobulin ameliorates ITP via activating Fc gamma receptors on dendritic cells. Nat. Med. 12, 688-692 (2006).

35. Boruchov, A.M. et al. Activating and inhibitory lgG Fc receptors on human DCs mediate opposing functions. J. Clin. Invest. 115, 2914-2923 (2005).

36. Lewkowich, I.P. et al. CD4+CD25+ T cells protect against experimentally induced asthma and alter pulmonary dendritic cell phenotype and function. J. Exp. Med. 202, 1549-1561 (2005).

37. Polte, T., Hennig, C. \& Hansen, G. Allergy prevention starts before conception: maternofetal transfer of tolerance protects against the development of asthma. J. Allergy Clin. Immunol. 122, 1022.e5-1030.e5 (2008).

38. Abrahamson, D.R., Powers, A. \& Rodewald, R. Intestinal absorption of immune complexes by neonatal rats: a route of antigen transfer from mother to young. Science 206, 567-569 (1979).

39. Hanson, D.G. Ontogeny of orally induced tolerance to soluble proteins in mice. I. Priming and tolerance in newborns. J. Immunol. 127, 1518-1524 (1981).

40. Benlounes, N. et al. Intestinal transport and processing of immunoglobulin G in the neonatal and adult rat. Biol. Neonate. 67, 254-263 (1995).

41. da Costa, P.S., de Macedo, M.S. \& Perini, A. Suppression of mouse lgE response by immune complexes. J. Allergy Clin. Immunol. 86, 496-502 (1990).

42. Caulfield, M.J. \& Shaffer, D. Immunoregulation by antigen/antibody complexes. I. Specific immunosuppression induced in vivo with immune complexes formed in antibody excess. J. Immunol. 138, 3680-3683 (1987).

43. Sinclair, N.R. et al. Regulation of the immune response. X. Antigenantibody complex inactivation of cells involved in adoptive transfer. J. Immunol. 113, 1493-1500 (1974).

44. Machiels, J.J. et al. Allergic bronchial asthma due to Dermatophagoides pteronyssinus hypersensitivity can be efficiently treated by inoculation of allergen-antibody complexes. J. Clin. Invest. 85, 1024-1035 (1990).

45. Machiels, J.J., Lebrun, P.M., Jacquemin, M.G. \& Saint-Remy, J.M. Significant reduction of nonspecific bronchial reactivity in patients with Dermatophagoides pteronyssinus-sensitive allergic asthma under therapy with allergen-antibody complexes. Am. Rev. Respir. Dis. 147, 1407-1412 (1993).

46. Mowat, A.M. Anatomical basis of tolerance and immunity to intestinal antigens. Nat. Rev. Immunol. 3, 331-341 (2003).

47. Worbs, T. et al. Oral tolerance originates in the intestinal immune system and relies on antigen carriage by dendritic cells. J. Exp. Med. 203, 519-527 (2006).

48. Nimmerjahn, F. \& Ravetch, J.V. Fcgamma receptors as regulators of immune responses. Nat. Rev. Immunol. 8, 34-47 (2008).

49. van Montfoort, N. et al. A novel role of complement factor C1q in augmenting the presentation of antigen captured in immune complexes to CD8+ T lymphocytes. J. Immunol. 178, 7581-7586 (2007).

50. Qiao, S.W. et al. Dependence of antibody-mediated presentation of antigen on FcRn. Proc. Natl. Acad. Sci. USA 105, 9337-9342 (2008).

51. Maynard, C.L. et al. Regulatory T cells expressing interleukin 10 develop from Foxp3(+) and Foxp3(-) precursor cells in the absence of interleukin 10. Nat. Immunol. 8, 931-941 (2007).

52. Casas, R. \& Bjorksten, B. Detection of Fel d 1-immunoglobulin G immune complexes in cord blood and sera from allergic and non-allergic mothers. Pediatr. Allergy Immunol. 12, 59-64 (2001).

53. Lutz, M.B. et al. An advanced culture method for generating large quantities of highly pure dendritic cells from mouse bone marrow. J. Immunol. Methods 223, 77-92 (1999). 